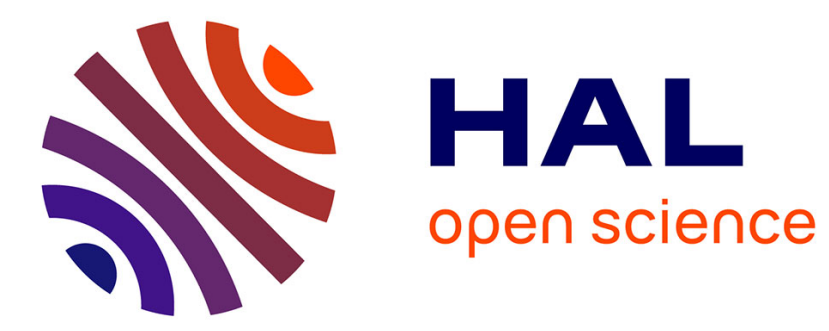

\title{
Main results of the European PASSAM project on severe accident source term mitigation
}

\author{
T. Albiol, L. Herranz, E. Riera, C. Dalibart, T. Lind, A. del Corno, T. \\ Kärkelä, N. Losch, B. Azambre, C. Mun, et al.
}

\section{- To cite this version:}

T. Albiol, L. Herranz, E. Riera, C. Dalibart, T. Lind, et al.. Main results of the European PASSAM project on severe accident source term mitigation. Annals of Nuclear Energy, 2018, 116, pp.42-56. 10.1016/j.anucene.2018.02.024 . hal-02874506

\section{HAL Id: hal-02874506 https://hal.science/hal-02874506}

Submitted on 25 Jan 2021

HAL is a multi-disciplinary open access archive for the deposit and dissemination of scientific research documents, whether they are published or not. The documents may come from teaching and research institutions in France or abroad, or from public or private research centers.
L'archive ouverte pluridisciplinaire HAL, est destinée au dépôt et à la diffusion de documents scientifiques de niveau recherche, publiés ou non, émanant des établissements d'enseignement et de recherche français ou étrangers, des laboratoires publics ou privés. 


\title{
Main results of the European PASSAM project on severe accident source term mitigation
}

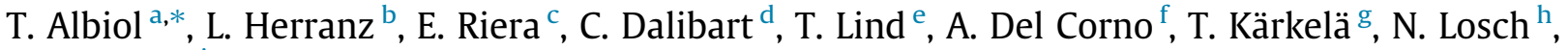 \\ B. Azambre ${ }^{\mathrm{i}}$, C. Mun ${ }^{\mathrm{a}}$, L. Cantrel ${ }^{\mathrm{a}}$
}

a IRSN, Centre de Cadarache, BP3, 13115 Saint Paul les Durance Cedex, France

${ }^{\mathrm{b}}$ CIEMAT, Avda. de la Complutense, 40, Madrid 28040, Spain

${ }^{\mathrm{c}}$ CSIC, Serrano 144, Madrid 28006, Spain

${ }^{\mathrm{d}}$ EDF, 12-14 avenue Dutriévoz, 69628 Villeurbanne Cedex, France

${ }^{\mathrm{e}}$ PSI, 5232 Villigen, Switzerland

${ }^{\mathrm{f}}$ RSE, via Rubattino 54, 20134 Milano, Italy

${ }^{g}$ VTT, BI7, Biologinkuja 7, P.O. Box 1000, FI-02044 VTT, Finland

${ }^{\mathrm{h}}$ AREVA GmbH, Seligenstaedter Strasse 100, 63791 Karlstein, Germany

${ }^{\mathrm{i}}$ Université de Lorraine, LCPA2MC, Institut Jean Barriol, Rue Demange, 57500 Saint Avold, France

\section{A R T I C L E I N F O}

\section{Article history:}

Received 29 November 2017

Received in revised form 6 February 2018

Accepted 9 February 2018

Available online 21 February 2018

\section{Keywords:}

Nuclear safety

Accident mitigation

FCVS

PASSAM

\begin{abstract}
A B S T R A C T
The PASSAM (Passive and Active Systems on Severe Accident source term Mitigation) project was launched in the frame of the 7th framework programme of the European Commission. Coordinated by IRSN, this four year project (2013-2016) involved nine partners from six countries: IRSN, EDF and university of Lorraine (France); CIEMAT and CSIC (Spain); PSI (Switzerland); RSE (Italy); VTT (Finland) and AREVA GmbH (Germany).

It was mainly an R\&D project of experimental nature aimed at investigating phenomena that might enhance source term mitigation in case of a severe accident in a Nuclear Power Plant (NPP). Both existing systems (i.e., water scrubbing and sand bed filters plus metallic pre-filters) and innovative ones (i.e., high pressure sprays, electrostatic precipitators, acoustic agglomerators and, advanced zeolites and combined wet-dry filtration systems), were experimentally studied in conditions as close as possible from those anticipated for severe accidents.

This paper presents the main experimental results of the project which represent a significant extension of the current database on these existing or innovative mitigation systems. Application of some of these data for improving existing models or developing new ones should eventually enhance the capability of modelling Severe Accident Management measures and developing improved guidelines.
\end{abstract}

(c) 2018 Elsevier Ltd. All rights reserved.

\section{Introduction}

After the TEPCO Fukushima accident of March 2011, one of the main concerns of the nuclear industry has been the search for improved atmospheric source term mitigation systems. The motivation underneath stems from two major factors: venting of the containment building might be an essential accident management measure in order to prevent the loss of its mechanical integrity, but this containment venting might result in substantial radioactive releases if no efficient source term mitigation system is implemented.

Some countries like Sweden, Switzerland, Finland, Germany and France, had already implemented Filtered Containment Venting

\footnotetext{
* Corresponding author.

E-mail address: thierry.albiol@irsn.fr (T. Albiol).
}

Systems (FCVS) in the early 1990's as a means to enhance the safety of their Nuclear Power Plants (NPPs). The Netherlands, China and Bulgaria followed before the Fukushima accident. Many other countries have considered, and several of them decided on the implementation of FCVS more recently, in the post-Fukushima context.

This renewed interest for FCVS has stimulated new national R\&D programmes on this topic in several countries and new coordinated international activities, like writing a status report by a working group on the Analysis and Management of Accidents of the CSNI (Committee on the Safety of Nuclear Installations) of the OECD-NEA (Jacquemain et al., 2014), or launching the European Commission (EC) project on "Passive and Active Systems on Severe Accident source term Mitigation" (PASSAM) presented in this paper. 
After a short overview of the context, objectives and main features of the PASSAM project, this paper presents the various experimental studies which have been performed and highlights some of the major results obtained.

\section{PASSAM context, objectives and main features}

The industrial FCVS are essentially based on two approaches: "dry" and "wet" systems. In dry systems, large trapping surfaces are provided either by gravel or sand beds, or by metal fibers or by molecular sieves. In wet systems, trapping occurs in a liquid (water plus additives) pool as a consequence of several removal mechanisms the efficiency of which depends strongly on thermal-hydraulic conditions. These systems can be enhanced by including venturi scrubbers: water droplets injected into the gas stream capture aerosol particles and make them more easily trapped by subsequent filter systems.

In 2012, when launching the PASSAM programme, these systems, some of which were installed on NPPs, had been well characterized as regards aerosol retention efficiency, but to a far lesser extent as regards volatile iodine retention, including organic iodides. Indeed, more recent tests had been performed on FCVS for trying to improve the systems as regards organic iodide retention in water pools. Nevertheless the research on this specific aspect needed to be complemented. A lack of knowledge also appeared clearly for organic iodine retention in dry systems.

In parallel, several alternative and innovative approaches were appearing in the literature or are even already proposed by some vendors. Electric filtration systems were already widely used for many industrial applications, out of the nuclear field. Solutions based on molecular sieves (improved zeolites, metal organic frameworks, etc...) were also widely used as filter in many industrial processes. Many kinds of zeolite exist; a key point consisted of finding the most efficient zeolite for iodine species in severe accident conditions. Another promising innovative solution relied on the combination of wet and dry filter systems. Besides, as it is well known that, generally speaking, the filtration systems are less efficient for aerosol particles of some tenths of microns, some systems were being developed, aiming at agglomerating aerosol particles in order to get bigger particles which would be better filtered (acoustic systems, high pressure sprays ...). Implementing such a device upstream of a filtration system could overcome the decrease of filtration efficiency of sub-micron particles.

Another subject which had poorly been studied is the stability of the trapped fission products on the medium and long term (up to some days) following a nuclear accident. Indeed, the trapped fission products may be re-vaporized and/or re-entrained due to surrounding conditions relevant to an accident and more especially, due to continuous irradiation, coupled to continuous flow-rate (if the venting system remains open), and to high temperature and humidity. Indeed the re-entrainment of trapped aerosols was tested in different small scale facilities and, at larger scale, in the international ACE programme (Allelein et al., 2009) where the aerosol loaded filters (dry and wet filters) were operated with clean gas and the aerosol concentrations of the gas downstream of the filters were measured. Nevertheless, no data on delayed release, under typical FCVS conditions (including irradiation) both for trapped aerosols and gaseous iodine forms, could be found in the open literature.

In this context, the PASSAM project was proposed to explore potential enhancements of existing source term mitigation devices and check the ability of innovative systems to achieve even larger source term attenuation. Heavily relying on experiments, the PASSAM project aimed at providing new data on the capability and reliability of a number of systems related to FCVS: pool scrubbing systems, sand bed filters plus metallic prefilters, acoustic agglomerators, high pressure sprays, electrostatic precipitators, improved zeolites and combination of wet and dry systems. Nonetheless, the scope of some of the PASSAM research topics - such as fission products and aerosol retention in water pools - goes beyond FCVS and might be applied for accident situations other than containment venting, e.g. for fission product scrubbing in the wetwell of a BWR or for Steam Generator Tube Rupture (SGTR) accidents with a submerged secondary side.

Besides an extension of the existing experimental database on existing and innovative filtration systems, the focus was put on trying to get a deeper understanding of the phenomena underlying their performance and to develop models/correlations that allow modelling of the systems in severe accident analysis codes, like ASTEC (Chatelard et al., 2015).

So, the PASSAM project was launched under the 7th framework programme of EURATOM for four years, formally from January 2013 to December 2016, and practically up to March 2017. Gathering 9 organizations (IRSN, EdF and University of Lorraine, France; CIEMAT and CSIC, Spain; PSI, Switzerland; RSE, Italy; VTT, Finland; and AREVA GmbH, Germany) and coordinated by IRSN, the project involved about 400 person-months and the associated cost was more than $5 \mathrm{M} €$.

The PASSAM project planning was rather linear as a whole, with three conceptual phases:

- set-up of organizational bases and of experimental facilities (2013);

- execution of experimental campaigns (mid 2013 to end 2016);

- in depth analysis of the experimental results and project wrapup (mid 2015 to early 2017).

The first phase included a literature survey on the existing and innovative systems to be experimentally studied in the project (Herranz et al., 2013). This survey confirmed, with more details, the anticipated gaps of knowledge and so it allowed optimizing the test matrices for each experimental work-package (Herranz et al., 2014a). It ended up with an open workshop held in Madrid (Spain) in February 2014 (PASSAM, 2014).

The experimental studies, which constitute the largest part of the PASSAM activities, are described in the next section of this paper together with the rationale for exploring each of the system studied and a selection of some major results.

The last phase of PASSAM consisted mainly of two points. An indepth analysis of the experimental results allowed developing some models and/or correlations from the experimental results. The corresponding outcomes are presented together with the experimental results in the next section of this paper.

In parallel, the project outputs were optimized so that nuclear community could easily benefit from the research conducted: a final PASSAM workshop was organized on February 28th and March 1st, 2017 in Paris (France), the final synthesis report of the project was made available in the open literature and several PASSAM papers were issued in scientific journals and conferences by the PASSAM partners.

\section{PASSAM experimental studies and selected major results}

\subsection{Experimental studies of pool scrubbing systems (leader PSI)}

Severe accidents in nuclear power plants are characterized by a damage of the reactor core, and subsequent potential for release of radioactive substances into the environment. In certain sequences, the radioactivity in the aerosol or gas form may be transported through a liquid pool, in which a large fraction of the radioactivity 
may be retained by transfer of aerosol particles and gas phase species into the liquid. Such instances are, e.g., wet scrubbers in filtered containment venting systems (FCVS), suppression pools in the boiling water reactors (BWR), or the secondary side of the steam generators during steam generator tube rupture (SGTR) incidents if the secondary side were to be flooded.

Whereas the retention potential of liquid pools has been studied in several experimental programs for both aerosol and gas phase species, the literature survey carried out in the beginning of the PASSAM project (Herranz et al., 2014b) revealed several significant gaps in the knowledge regarding pool scrubbing. Based on the survey, the following investigations were carried out in the PASSAM project to provide experimental data for a more comprehensive description of pool scrubbing (Lind et al., 2015):

- Hydrodynamic characterization of pools under high velocity jet injection conditions relevant to steam generator tube rupture (SGTR);

- Detailed hydrodynamic characterization of the pool combined with aerosol retention including the effect of impurities and surfactants in the water;

- Aerosol retention in the pool focusing on the effect of injection regime and steam mass fraction;

- Iodine release from the pool due to irradiation, chemical, and thermal-hydraulic effects in the intermediate to long time frame;

- The retention of organic iodide in the pool, and the effect of additives and submerged structures on the retention;

A summary of the investigations is given in this paper. Based on the results, models and correlations were developed for improved description of the pool scrubbing phenomena.

\subsubsection{Pool scrubbing under jet injection regime (CIEMAT)}

A series of tests were performed in 2016 in the CIEMAT PECA facility, focusing on aerosol retention close to the injection point under high gas velocities (i.e., the jet injection regime). Two major boundary conditions for retention at the inlet of the pool were considered: the gas mass flow rates (i.e., gas injection velocity) and the saturation state of the gas entering the pool. The former was controlled through the non-dimensional Weber number (We is the ratio between inertia and surface tension forces) and the latter through the gas saturation ratio ( $\mathrm{S}$ is the ratio between steam pressure in the carrier gas and saturation pressure at the pool temperature). The test matrix is given In Table 1, in terms of both nondimensional quantities and associated physical variables.

Despite the exploratory nature of these experiments (further extension is planned beyond the PASSAM framework), some interesting insights have been gathered: a deep knowledge of submerged jet hydrodynamics is necessary to fully understand the scrubbing mechanisms; the scrubbing efficiency grows with the non-dimensional Weber number (We) up to values around
$99-99.5 \%$, but data seem to indicate that beyond a certain We threshold value (around $2 \cdot 10^{6}$ ) no further net growth can be credited as data uncertainties prevent more accurate statements; saturation ratio, though, was not a primary influencing variable, which indicates that most scrubbing was due to mechanical phenomena, as inertial impaction (and maybe interception). Fig. 1 summarizes the results obtained in terms of scrubbing efficiency.

Among key factors for forthcoming tests, it was found that the total injected mass has to be increased so that, even under high retention conditions, outlet measurements are not jeopardized by the little amount of mass collected; sampling and multiple characterization of aerosols is of utmost importance, particularly downstream the pool; pool water depth has to be included as a matrix variable since it affects multiple factors intervening in scrubbing, and, finally, the matrix extension should be extended to soluble particles $\left(\mathrm{SiO}_{2}\right.$ was used in PASSAM) and multiple hole injectors.

3.1.2. Pool scrubbing and hydrodynamics in natural water, sea water and in the presence of additives (RSE)

Tests using the RSE SCRUPOS facility aimed as a first step, to bubble studies and as a second step, to aerosol retention in natural water, sea water and in the presence of additives. The measurements relied mainly on three techniques: optical probe, photo camera and video camera.

The tests on bubble hydrodynamics were performed with injection velocities from 16 to $74 \mathrm{~m} / \mathrm{s}$ so to have different flow regimes. In fact, in this bare pool configuration, the different flow conditions generate different gas patterns in the injection zone, but after only 20-30 cm, big bubbles are broken into smaller ones, typical of a "bubble regime": the local void fraction distribution vs bubble chord at 23, 62 and $82 \mathrm{~cm}$ from the nozzle with an injection velocity of a bubble regime (Fig. 2a) and of a jet regime (Fig. 2b) are similar. In the bubble regime and in the three tested liquid phases (natural water, sea water and in the presence of additives), the bubble size distributions and velocities are similar (Fig. 3c and Fig. 4). In jet regime and in the injection zone, the bubble size distributions in sea water and in water with surfactant are bimodal with globule bubble formation smaller than that in demineralized water (Fig. 3f and Fig. 4). This effect is due to the higher tendency to break-up in the case of the surfactant because of the lower surface tension and for the sea water because of the inhibited coalescence caused by the presence of electrolytes.

Based on experiments performed with $\mathrm{SiO}_{2}$ particles of 0.4 and $1 \mu \mathrm{m}$, higher retention efficiencies were measured in sea water and in water with surfactant compared to demineralized water due to different bubble sizes and velocities (Fig. 4). The tests allowed validating a simplified model to describe the evolution of the bubbles inside the pool. One major recommendation is that bubble size and break up model assumptions should take into account both aerosol deposition surfaces (function of size and shape which are evolving during rising) and distribution of rising velocity of bubble swarms. Finally it was confirmed that ad-hoc devices (obstacles, grids, etc.)

Table 1

Boundary conditions ${ }^{\#}$ of the PSP tests.

\begin{tabular}{|c|c|c|c|c|c|c|c|}
\hline Test & $\begin{array}{l}\mathrm{T}_{\text {gas }} \\
{ }^{\circ} \mathrm{C}\end{array}$ & $\begin{array}{l}\mathrm{T}_{\text {pool }} \\
{ }^{\circ} \mathrm{C}\end{array}$ & $\begin{array}{l}Q_{\text {steam }} \\
1 / \text { min }\end{array}$ & $\begin{array}{l}Q_{\text {total }} \\
1 / \mathrm{min}\end{array}$ & $\begin{array}{l}\mathrm{X}_{\text {steam }} \\
\% \text { (vol) }\end{array}$ & We & $S$ \\
\hline PSP0 & 100 & 35 & 5 & 160 & 3.13 & $2.36 \mathrm{E}+05$ & 0.59 \\
\hline PSP1 & 100 & 35 & 6 & 210 & 2.86 & $1.02 E+06$ & 0.56 \\
\hline PSP2 & 100 & 35 & 9 & 310 & 2.9 & $2.21 E+06$ & 0.61 \\
\hline PSP3 & 100 & 35 & 15 & 460 & 3.26 & $4.87 E+06$ & 0.79 \\
\hline PSP4 & 100 & 35 & 30 & 460 & 6.52 & $4.87 E+06$ & 1.57 \\
\hline PSP5 & 100 & 35 & 45 & 460 & 9.78 & $4.87 E+06$ & 2.36 \\
\hline PSP6 & $\mathrm{T}_{\text {env }}$ & $\mathrm{T}_{\mathrm{env}}$ & 0 & 460 & 0 & $4.87 E+06$ & 0.00 \\
\hline
\end{tabular}

\footnotetext{
\# All the experiments were conducted with $1 \mu \mathrm{m} \mathrm{SiO}{ }_{2}$ particles and $0.30 \mathrm{~m}$ submergence.
} 


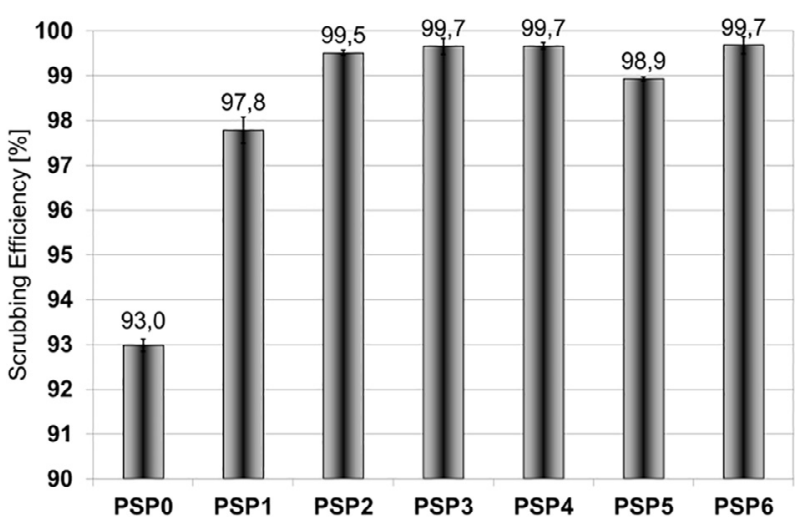

Fig. 1. Retention efficiency in the PSP experiments.

are required to favor bubble fragmentation and so, to increase bubble surface and aerosol retention.

\subsubsection{Pool hydrodynamics under SGTR conditions (PSI)}

To understand the aerosol transport in the steam generator secondary side during SGTR, the hydrodynamic behaviour of the twophase flow needs to be characterized. Under these conditions, the two-phase flow is expected to be very complex due to the high gas velocities and complicated geometry of the steam generator secondary side. Many experiments were performed in the PSI TRISTAN facility in the PASSAM frame. The facility could be equipped with a tube bundle consisting of 221 steam generator tubes, or with a single tube in the center of the facility (Fig. 5). A specific wire mesh sensor technology for measurement of 3D flow patterns and void fractions was successfully developed, complemented by application of imaging techniques for very small bubbles. The tests covered a large flow rate range from 50 to $450 \mathrm{~kg} / \mathrm{h}$ through the tube break, different break sizes (1-D and 0.5-D) and break shapes (guillotine and fish-mouth) as well as four different break-tosensor distances $(100,650,1125$ and $2500 \mathrm{~mm})$. The facility was operated at ambient conditions.

The foremost observation of the flow hydrodynamics relevant to SGTR was the existence of very large volumes of gas with varying shapes (Fig. 6) and the chaotic, dynamic behaviour of the flow. The tube bundle showed a significant confining effect to the spreading of the gas jet with less penetration depth than in a bare pool (Fig. 7). The bubble size distributions were bimodal with a large number of small bubbles with the spherical equivalent diameter of 5-10 $\mathrm{mm}$ and with a second peak at bubble equivalent diameters larger than $100 \mathrm{~mm}$. Even though small in number, the large bubbles represented a considerable amount of gas phase volume. The contribution of bubbles too small to be detected by a wire-mesh sensor was found to be minor with less than $5 \%$ of the interfacial area being present in the bubbles with diameters smaller than $3 \mathrm{~mm}$.

The interfacial area concentration is important to determine because it is a major parameter defining the mass transfer from the gas bubbles to the liquid. Therefore, considerable efforts were made to determine it under the challenging flow conditions of the present work. The results show that with similar injection flow rates, the interfacial area concentration was higher in the tube bundle than in the bare pool, presumably due to the break-up of the bubbles in the tube bundle due to the interaction of the gas jet with the tubes. However, the difference was not large enough to give a straightforward explanation for the large increase in the aerosol retention in the tube bundle as observed in earlier investigations (Lind et al., 2011), and further work is required to interpret the results and apply them to the understanding of the fission product retention in the liquid pools under different hydrodynamic conditions. The results of the investigation showed the confining effect of the tube bundle in the pool, and highlighted the highly dynamic nature of the flow (Betschart et al., 2015).

Current pool scrubbing code modelling implicitly assumes low injection rates and hence only two-phase gas-liquid interactions are considered. In jet injection regimes, three phase liquid-gasdroplet model is required for accurate estimates of the aerosol removal. The current work on the hydrodynamics of the jet injection regimes has permitted valuable insights on the dominating fluid flow regimes. In particular, the detailed bubble size, shape, interfacial area and velocity data will allow more credible estimates of the multiphase phenomena than corresponding models in low injection regimes.

\subsubsection{Medium/long term stability of iodine in water pools (IRSN)}

The medium/long-term stability of retained iodine in wet scrubbers was investigated in the IRSN EPICUR facility. This facility allows working under irradiation $\left({ }^{60} \mathrm{Co}\right.$ source $)$ with labelled iodine $\left({ }^{131} \mathrm{I}\right)$, in representative severe accident conditions, and with online speciation and measurement of iodine aerosol and gaseous species (molecular iodine $\left(\mathrm{I}_{2}\right)$ and organic iodine) released from the irradiation vessel. These EPICUR tests were complemented by laboratory scale tests to study the $\mathrm{pH}$ evolution of various solutions

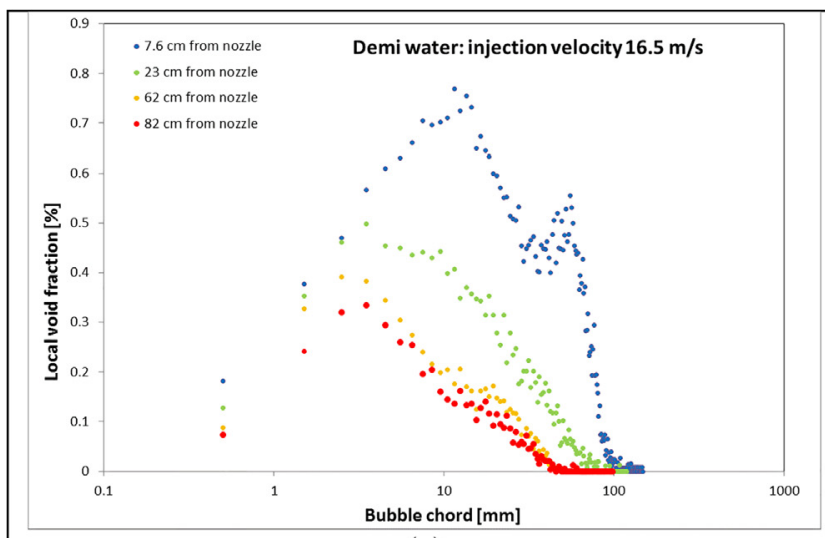

(a)

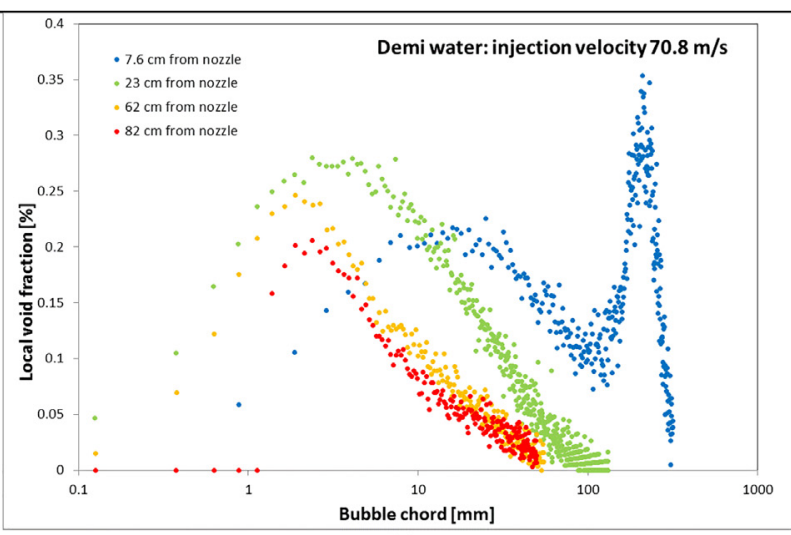

(b)

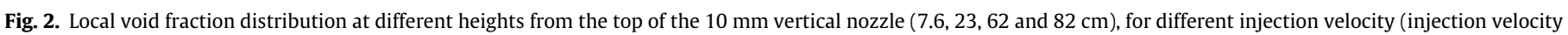
$16.5 \mathrm{~m} / \mathrm{s}$ with mass flow rate $5.7 \mathrm{~kg} / \mathrm{h}$ - bubble regime (a) and injection velocity $70.8 \mathrm{~m} / \mathrm{s}$ with mass flow rate $24 \mathrm{~kg} / \mathrm{h}$ - jet regime (b)). 


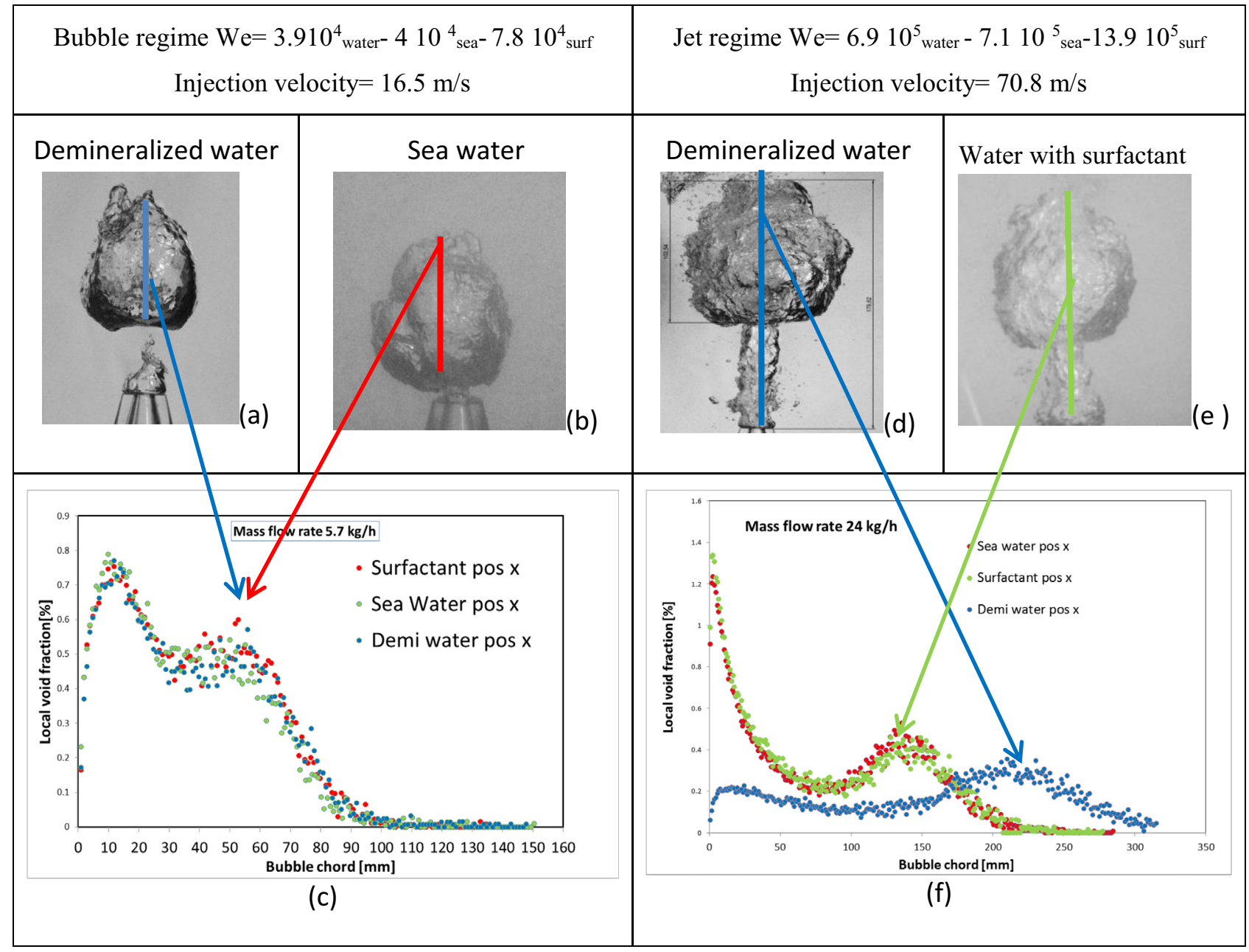

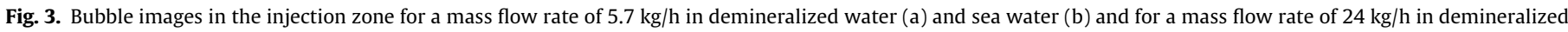

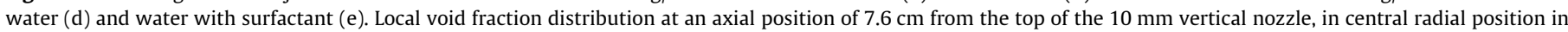
three different liquids for mass flow rates of $5.7 \mathrm{~kg} / \mathrm{h}$ (bubble regime) (c) and $24 \mathrm{~kg} / \mathrm{h}$ (jet regime) (f).

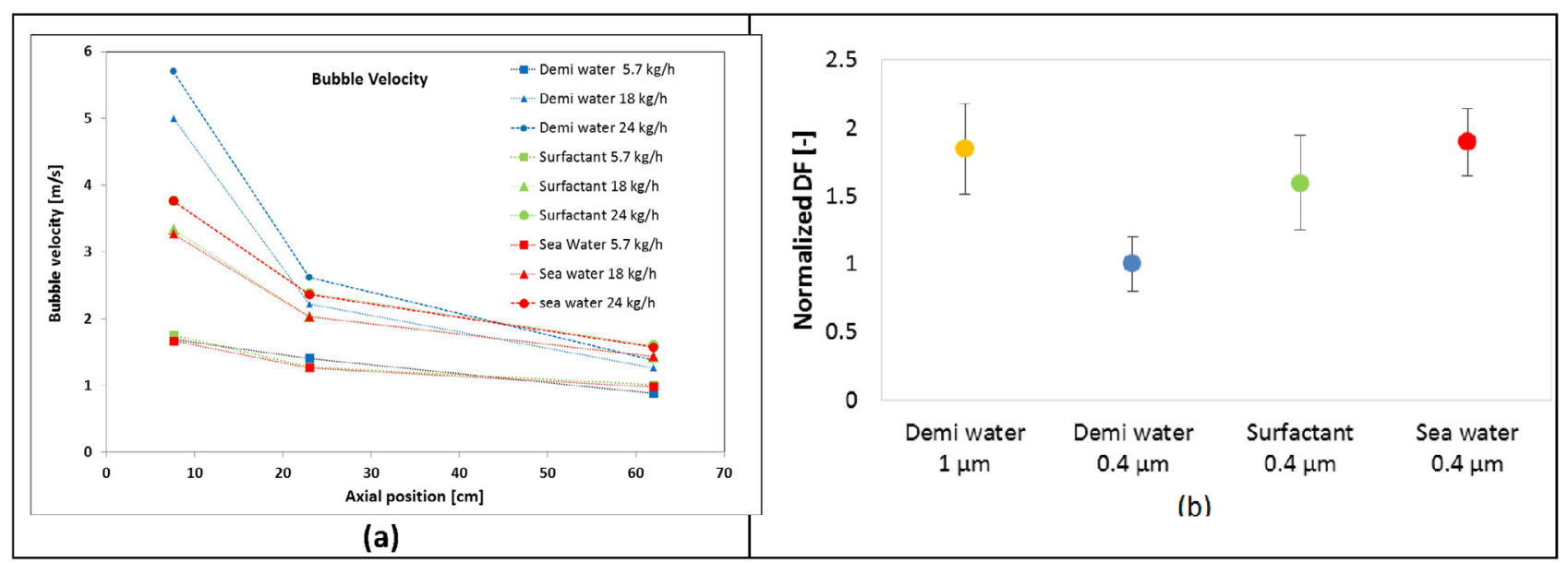

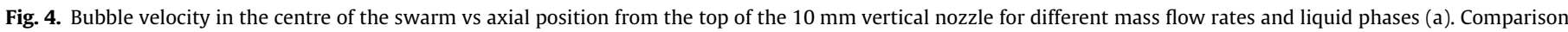

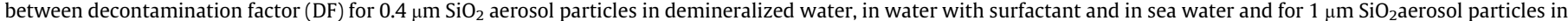

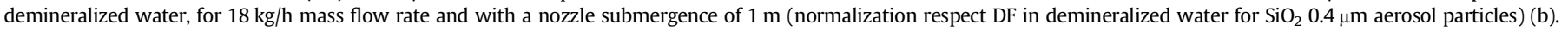

containing the major components which are usually used in pool scrubber solutions.

In addition to more detailed results, three major practical outputs can be drawn from the experimental results. Firstly, under radiation, molecular iodine chemical release and transport would occur from non-buffered solutions due to a $\mathrm{pH}$ decrease, while no direct molecular iodine chemical release and transport would occur from buffered solutions. So, the necessity of maintaining a 


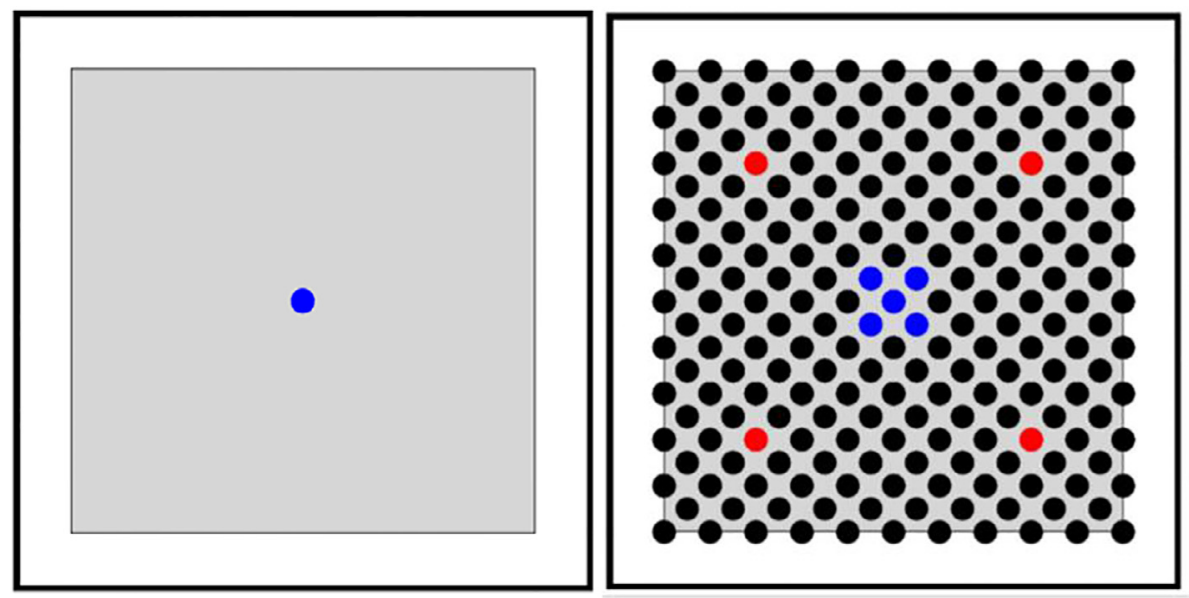

Fig. 5. Cross-sections of the facility for the two geometries, a) single tube, and b) tube bundle.
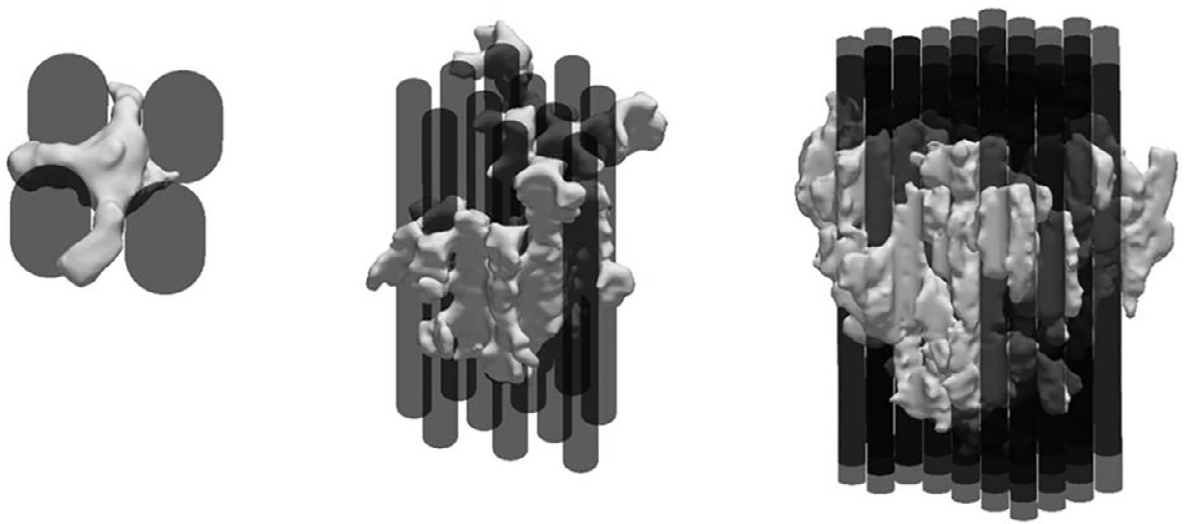

Fig. 6. Selected bubbles for the tube bundle set-up.
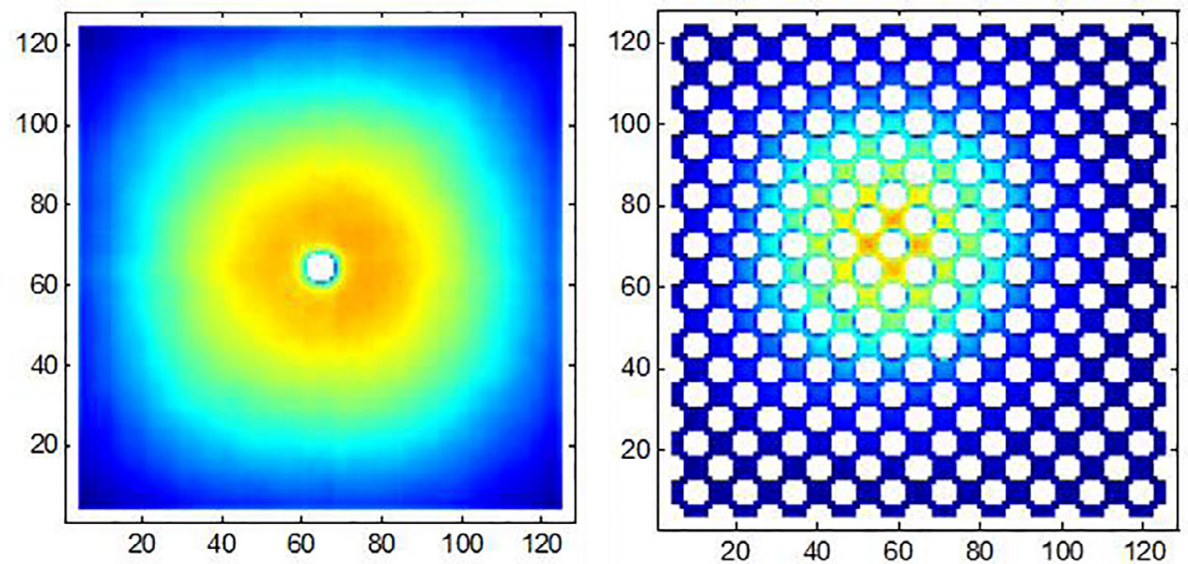

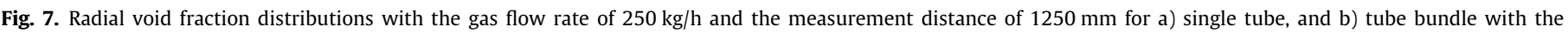
guillotine break.

high $\mathrm{pH}$ value all along the accident was evidenced (Fig. 8). Secondly, when the water pool is buffered ( $\mathrm{pH}$ maintained over 9.5), the experimental post-test iodine mass balance is low (between 68 and 50\% of iodine recovered only). The analysis (modelling) of the tests in alkaline conditions, coupled to the analysis of other tests (out of the PASSAM scope) allows to conclude on a possible high contribution of the HOI species to the global iodine release from the solution, although no direct iodine release was measured in the tests. Finally, under evaporating conditions (or even more, under boiling conditions), which would occur in a pool scrubber type FCVS during a real accident, mechanical entrainment could lead to significant iodine species release. So, the necessity of 


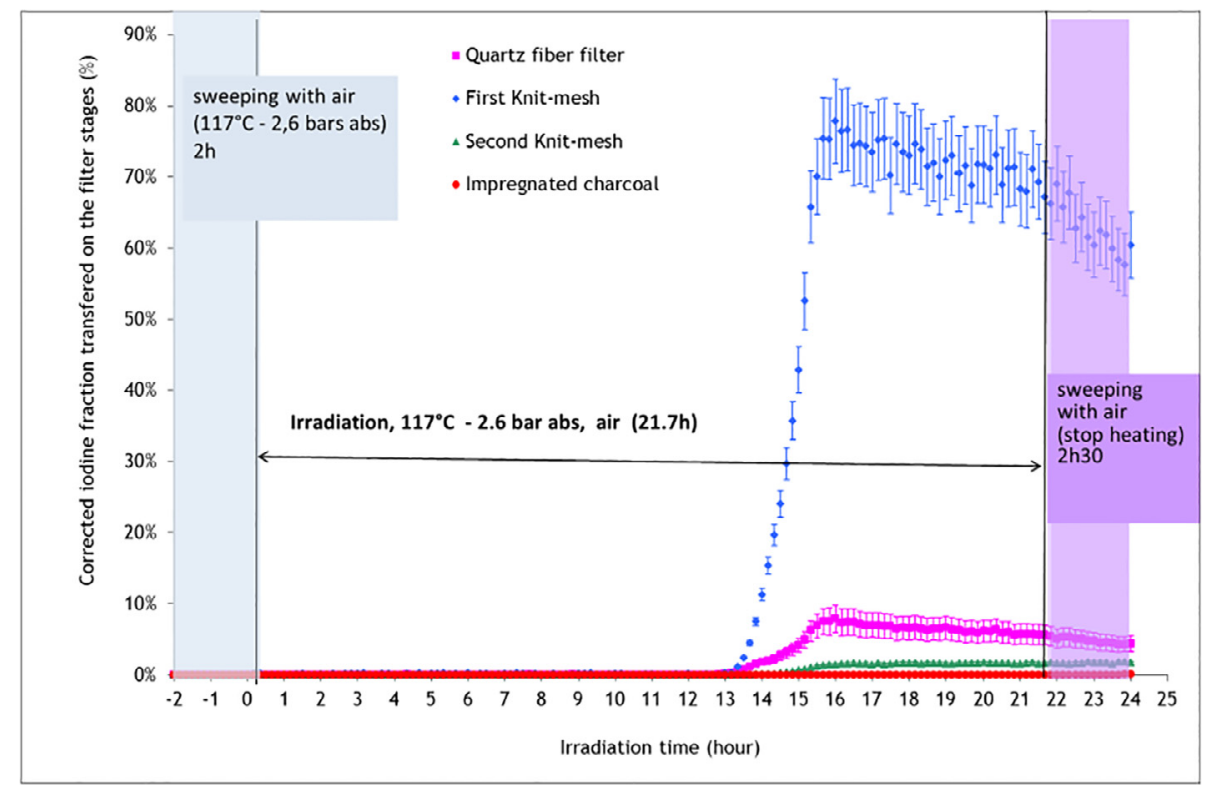

Fig. 8. Gaseous iodine $\left(I_{2}\right)$ release from a non-buffered solution under irradiation at 2.9 k.Gy.h ${ }^{-1}$.

designing an optimized pool scrubber with droplet separator and of ensuring a sufficient cooling of pool scrubbers to avoid evaporating/boiling conditions was also demonstrated.

\subsubsection{Retention of organic iodine in water pools (AREVA)}

Experiments at laboratory scale (AREVA VESPER34 facility, Fig. 9) were performed on the influence of scrubbing liquid composition, of mixing elements and of temperature. The additives often used in commercial scrubbers are $\mathrm{NaOH}$ for $\mathrm{pH}$ control and $\mathrm{Na}_{2} \mathrm{~S}_{2}-$ $\mathrm{O}_{3}$ (sodium thiosulfate) as primary reactant. The $\mathrm{CH}_{3} \mathrm{I}$ retention performance could not be further enhanced by increasing the sodium thiosulfate concentration. Yet the $\mathrm{CH}_{3} \mathrm{I}$ retention performance in the scrubber could be moderately increased by: Aliquat 336 (quaternary ammonium salt serving as phase transfer catalyst); mixing elements (increase of residence time and of metallic surface); increased temperature. However, if Aliquat scrubbing liquid is used, the retention performance is not further increased by mixing elements nor by increased temperature (a reduction of $\mathrm{CH}_{3} \mathrm{I}$ retention was even observed above $110^{\circ} \mathrm{C}$ ). It was not possible to reach high $\mathrm{CH}_{3} \mathrm{I}$ retention performance with the studied parameters (additive concentrations, geometries ...), under the conditions used in the tests. The application of sliding pressure to AREVA FCVS (scrubber is operated close to containment pressure) results already in increased pool temperatures and thus the potential of $\mathrm{CH}_{3} \mathrm{I}$ retention is seen as maxed out. So AREVA's conclusion is that alternative filtration methods (e.g. dry filtration) are necessary to reach a qualitative step towards high $\mathrm{CH}_{3} \mathrm{I}$ retention (see part 3.7 of this paper).

\subsection{Experimental studies of sand bed filters plus metallic pre-filters (leader IRSN)}

Sand bed filters were decided to be implemented for the French PWRs in 1986 and all French NPPs in operation had been fitted with FCVS since the mid-1990's. Their initial design was based on a set of boundary conditions: containment pressure and temperature of 5 bar and $140{ }^{\circ} \mathrm{C}$, respectively; gas flow rate through the FCVS line of $3.5 \mathrm{~kg} / \mathrm{s}$; gas mixture composed of air (33 wt\%), steam (29 $\mathrm{wt} \%), \mathrm{CO}_{2}(33 \mathrm{wt} \%)$ and $\mathrm{CO}(5 \mathrm{wt} \%)\left(\mathrm{H}_{2}\right.$ risk was addressed later on); aerosol concentration of $0.1 \mathrm{~g} / \mathrm{m}^{3}$ with an Aerodynamic Mass Median Diameter (AMMD) of $5 \mu \mathrm{m}$. The initial objective consisted of obtaining a retention efficiency of $90 \%$ for

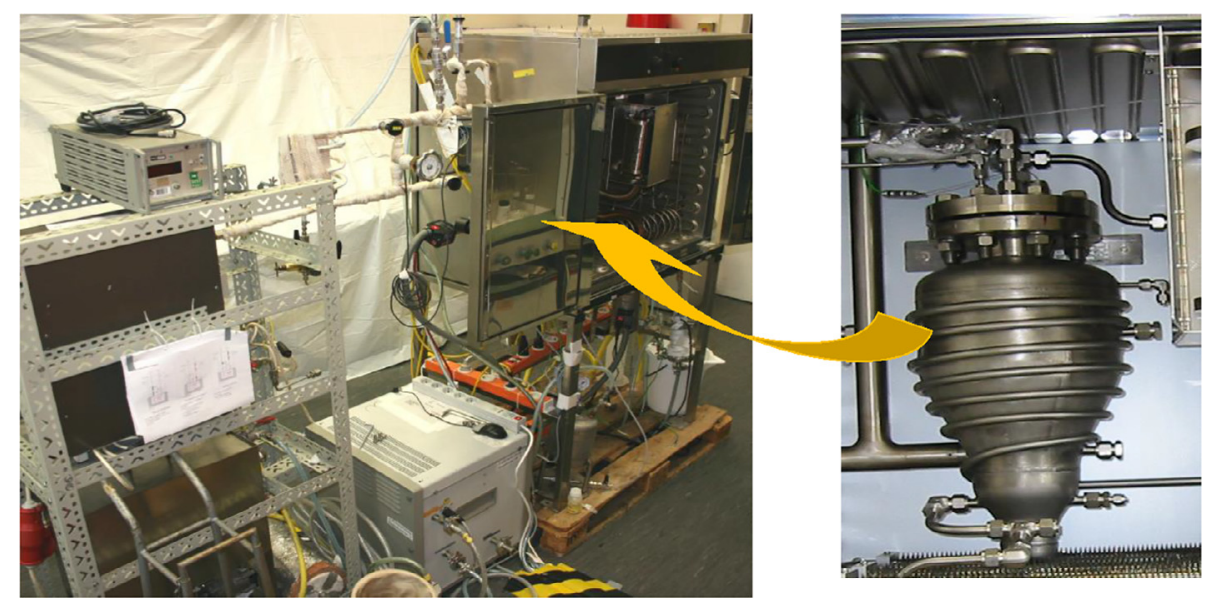

Fig. 9. AREVA VESPER34 facility. 
aerosol particles. The system was tested at two different scales: PITEAS and FUCHIA (Guieu, 2001). The PITEAS-filtration programme enabled to determine the characteristics of the filter material as well as its domain of use, and check its ability to meet the filtering efficiency criterion under accident conditions. The fullscale FUCHIA programme validated the thermo-hydraulic and filtering behaviour of the filtered venting line (without prefiltration).

Then, it was decided to add a metallic pre-filter upstream of the sand filter, in the containment building.

According to the experiments performed in the past, the minimal retention efficiency attributed to the sand bed plus metallic pre-filter system and used for safety analysis studies is:

- $99.9 \%$ for aerosol particles,

- $90 \%$ for inorganic gaseous iodine (due to trapping on metallic surfaces),

- $0 \%$ for organic gaseous iodine (no test done).

Despite the sound qualification of the system (Guieu, 2014), two domains appeared not (or not enough) covered and were investigated by IRSN in the PASSAM project:

- Filtration efficiency of gaseous molecular and organic iodines. Laboratory scale experiments showed no trapping of gaseous molecular iodine $\left(\mathrm{I}_{2}\right)$ or of iodomethane $\left(\mathrm{CH}_{3} \mathrm{I}\right)$ in the tested conditions on pure sand. Experiments on $\mathrm{I}_{2}$ retention by metallic prefilters showed that, in the tested conditions, a significant amount of $\mathrm{I}_{2}$ could be trapped. Tests on $\mathrm{CH}_{3} \mathrm{I}$ retention confirmed that neither sand filters nor coarse stainless steel wool can trap this species.

- Medium/long term stability of filtered fission products, in particular iodine, under severe accident conditions (temperature, flow-rate, pressure, humidity, irradiation). Two tests in the IRSN EPICUR facility were performed in order to check the medium/ long term stability of caesium iodide (CsI) aerosols trapped on a sand bed filter. It appears that in the tested conditions, which are rather close to these expected for severe accidents, CsI aero- sols are not stable and a significant release of $\mathrm{I}_{2}$ was observed (Fig. 10). Other similar tests have been performed with CsI aerosols trapped on metallic pre-filters. In this case, practically no release (or very low amounts) of iodine was observed. This may be explained by the affinity of iodine for stainless steel and the specific geometry of the pre-filter which presents a high specific surface area. Note that these results apply only to CsI aerosols. Other iodine compounds have not been tested.

\subsection{Experimental studies of acoustic agglomeration systems (leader CSIC - Contributor CIEMAT)}

Enhancement of agglomeration of sub-micron particles would result in increased particle sizes. So, the performance of filtration devices located downstream of an agglomerator system would be improved since the filtration efficiency shows a minimum in the range of $0.1-0.3 \mu \mathrm{m}$.

Acoustic agglomeration (AA) was first experimentally investigated in the 1930's and has been extensively studied over many years to understand its basic mechanisms. Its practical applications came a little later in the late 1940's with the development of powerful air-jet sound generators. Since then a broad research of potential applications have been investigated (Riera et al., 2003; Riera et al., 2006; Magill et al., 1989). The development of acoustic high-intense chambers as pre-conditioners of filters was specifically tested in some of these works. These studies found out optimum working conditions as regards exposure times, particle concentrations and distributions in the agglomeration chamber. As for the ultrasonic field optimization in nuclear severe accident conditions, it is known to be highly enhanced by particle polydispersion and unaffected by high pressure and temperatures.

Therefore, the main challenge for a potential application of AA in nuclear severe accident conditions consisted of checking the system performance under the anticipated working conditions during a severe accident. In the PASSAM frame, the effects of particle number concentration, treatment time and aerosol polydispersion were studied using an Acoustic Agglomerator $(21 \mathrm{kHz}$, $300 \mathrm{~W} /$ unit) developed by CSIC and implemented in the CIEMAT

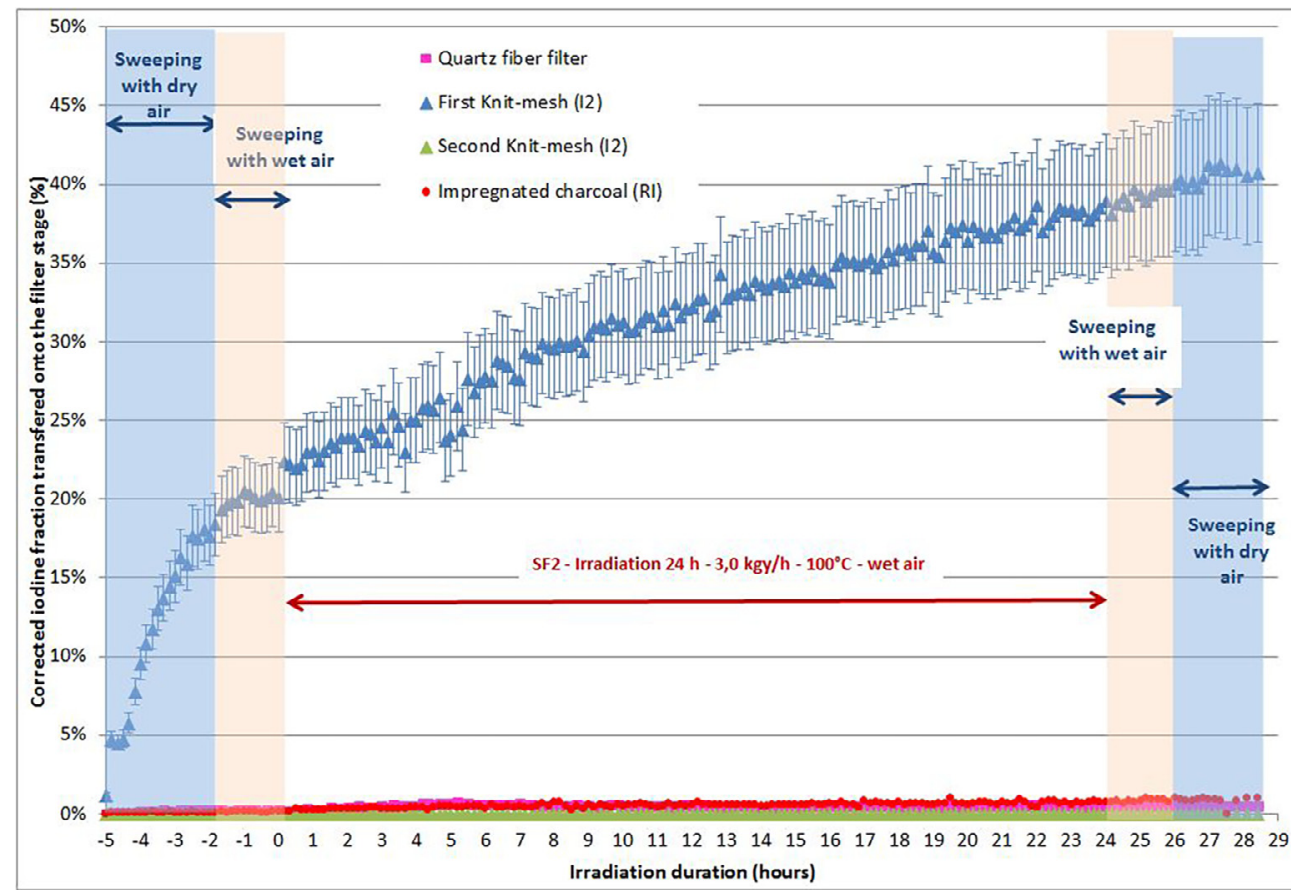

Fig. 10. Gaseous iodine $\left(\mathrm{I}_{2}\right)$ release from a sand filter loaded with CsI aerosols under irradiation at $3.0 \mathrm{kGy} \cdot \mathrm{h}^{-1}$ at $100{ }^{\circ} \mathrm{C}$. 

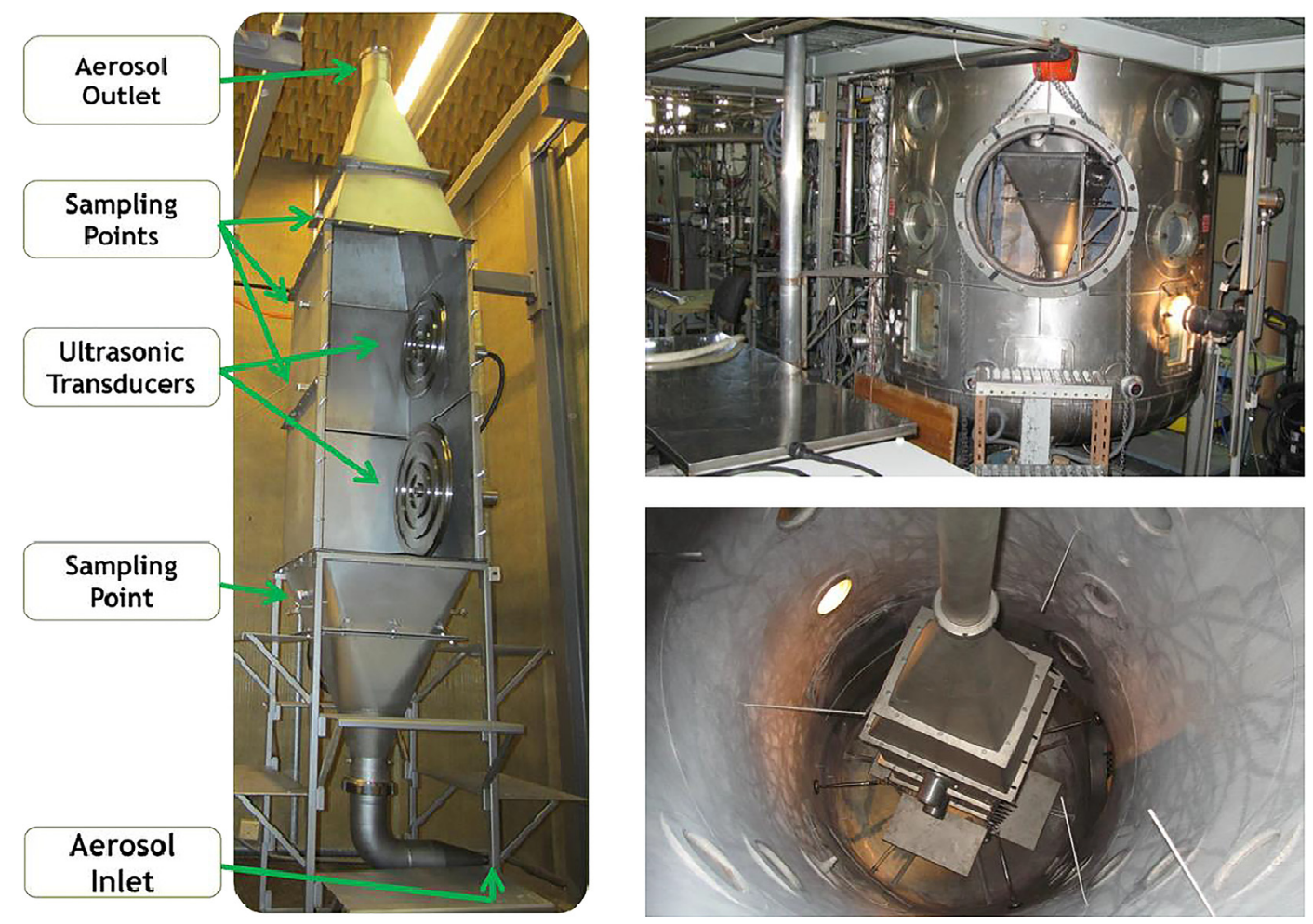

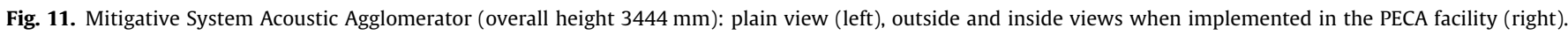

PECA facility, working with $\mathrm{SiO}_{2}$ and $\mathrm{TiO}_{2}$ aerosols (Fig. 11). Among the various experimental observations, we can mention the two following ones:

- a practical elimination of the smallest particles of the distribution (those between 0.1 and $0.3 \mu \mathrm{m}$ ),

- a slight shift of the distribution towards bigger sizes (up to 0.4 $\mu \mathrm{m}$ in terms of AMMD).

In addition, it can be noted that this agglomeration process also leads to a strong aerosol concentration decrease in the acoustic chamber.

\subsection{Experimental studies of high pressure spray agglomeration systems (leader RSE)}

High pressure sprays have been used in multiple industrial applications, including NPPs (High Pressure Core Spray System of BWR/5 and BWR/6). This type of spray works between 50 and 200 bar and can generate droplets smaller than $100 \mu \mathrm{m}$ at velocities near $100 \mathrm{~m} / \mathrm{s}$. Under these conditions, in addition to clean-up and cool-down atmospheres, they can also foster growth of submicron particles (Chuen-Jinn et al., 2005). However, few studies have addressed this potential capability and most of the researches on spray performance have been conducted for low pressure sprays (Powers and Burson, 1993). Therefore, high pressure spray application either as an additional system to decrease aerosol concentration or as an agglomerator in the pre-filter stage of a FCVS required new specific studies.

Experimental data were collected to investigate the phenomenology of the interaction between droplets generated by high-pressure sprays and fine particles transported throughout a venting line. For this purpose, measurements for droplet characterization and aerosol removal efficiency have been done. It has been highlighted that, to obtain a more effective removal of aerosol, smaller droplets and higher rates are necessary. These studies have been performed in the frame of PASSAM using the RSE SCRUPOS facility. The lab-scale experimentation, performed in a closed sampling chamber $0.5 \times 1.0 \times 1.5 \mathrm{~m}$ with a single-hole nozzle spray up to $130 \mathrm{bar}$, demonstrated the high removal efficiency that can be obtained for inert aerosols having $0.4,1$ and $2 \mu \mathrm{m}$ size.

The half-life of $1 \mu \mathrm{m} \mathrm{SiO} 2$ particles within the high-pressure spray chamber, turned out to be 50-100 times shorter than the half-life observed in a low-pressure spray system applied for removing a similar aerosol cloud (Fig. 12).

Within the sample volume of the chamber, it was found that a single-hole spray nozzle operating at 130 bar, can remove at least $99.9 \%$ of suspended micronic particles in a time of the order of a minute (about $1 \mathrm{~min}$ for $1 \mu \mathrm{m}$ particles, about $2 \mathrm{~min}$ for $0.4 \mu \mathrm{m}$ particles). No influence of the initial $\mathrm{SiO}_{2}$ aerosol concentration was observed for both $1 \mu \mathrm{m}$ and $0.4 \mu \mathrm{m}$ particles (Fig. 13).

When compared to low-pressure sprays, the removal efficiency, then, turned out much more significant, and encourages the application of this high-pressure technique in multi-nozzles and multistages configurations.

A model has been developed and provides a rather good agreement with experimental data.

\subsection{Experimental studies of electrostatic precipitators (leader VTT)}

Potential of electric filtration systems were discovered early in the 20th century, when corona discharge was found to remove particles from gas streams. Today many types of these filters exist including electrostatic precipitators (ESP), air ionizers and ion wind devices. Typically they are very efficient filtration systems with minimal resistance to the gas flow. They are applied for reduction of many industrial emissions, including coal and oil fired power plants, salt cake collection from black liquor boilers in pulp mills, and catalyst collection from fluidized bed catalytic cracker units in oil refineries. 


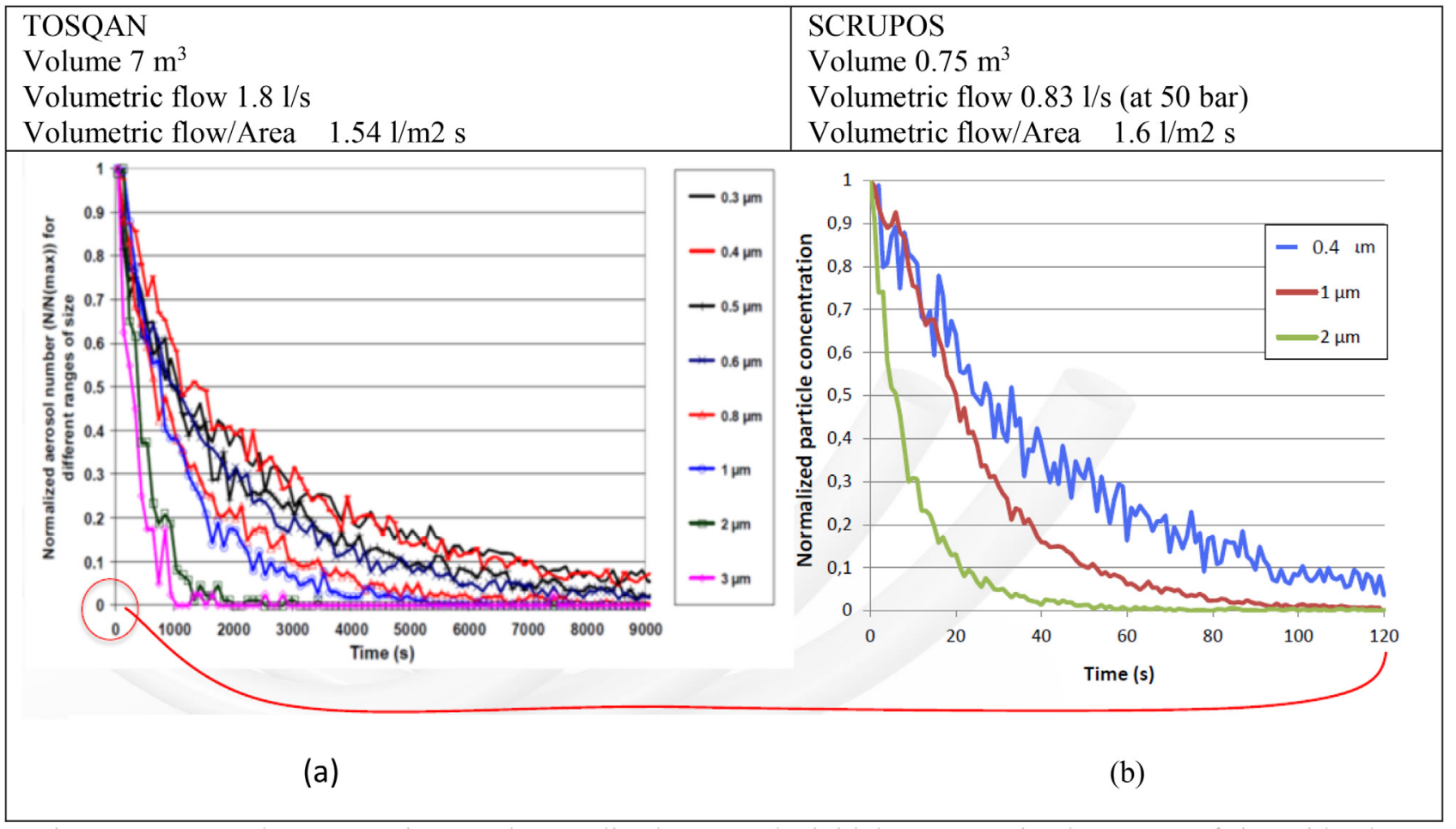

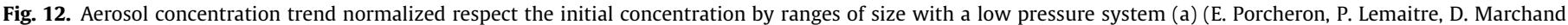
(2011) Aerosol Removal by Emergency Spray in PWR Containment, Journal of Energy and Power Engineering 5 600-611) and a high pressure system (b).

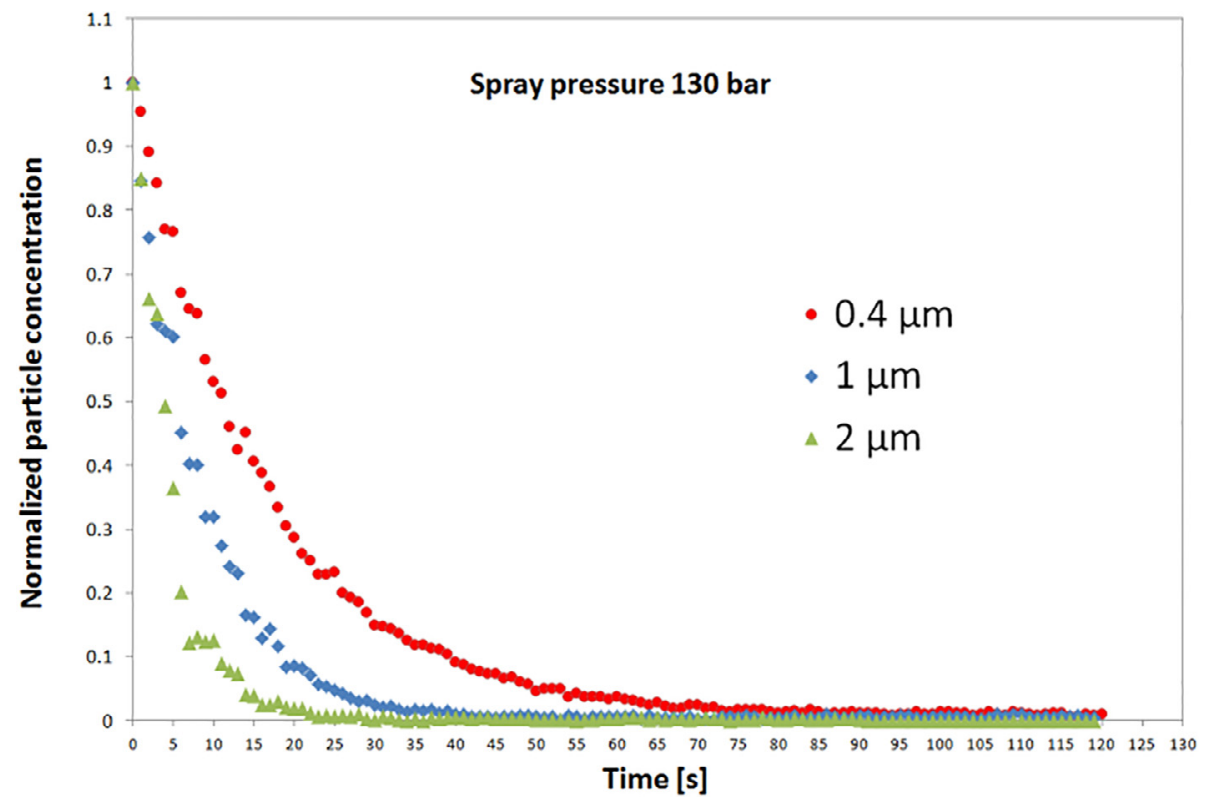

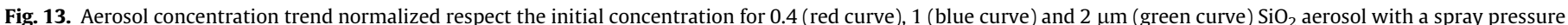
of 130 bar. (For interpretation of the references to colour in this figure legend, the reader is referred to the web version of this article.)

An ESP removes aerosols from gas flow due to forces induced by strong electric fields. In case particles do not get high enough charge for their collection, a pre-charging water mist can be sprayed to enhance particle growth in diameter and charging: This system is called Wet ESP (WESP). The operation temperature of a typical WESP at atmospheric pressure is limited to $90{ }^{\circ} \mathrm{C}$ and the pressure drop through the system is small. Typical filtration efficiency of a WESP for particles is between 99 and 99.9\%. In general, electric filtration systems operating at dry atmospheric conditions have a significant decrease in the filtration efficiency for particles with a diameter in a range from ca. 0.1 to $0.3 \mu \mathrm{m}$. The water mist sprayed inside the WESP enhances the filtration efficiency of particles regardless the particle initial size and thus no effective dropping in the filtration efficiency for any size of particles can be observed. Nonetheless, filtration efficiency can also be increased by maximizing the strength of the electric field (Chang et al., 2011) and the residence time within the precipitator. Other factors affecting efficiency are dust resistivity, gas temperature, chemical 
composition (of the dust and of the gas flow), and particle size distribution. WESP performance has been hardly tested for gaseous iodine, although preliminary tests were conducted on gaseous iodine filtration by VTT in 2011. In this case higher filtration efficiency was reached by adding an oxidation stage (ozone generator) that turns gaseous iodine species into iodine oxide particles. The oxidation stage was located before the WESP inlet.

Application of WESP under the foreseen conditions of a nuclear severe accident poses two major challenges:

- Conditions still not explored, like radiation and high temperatures $\left(>90^{\circ} \mathrm{C}\right.$ ) and pressures ( $>1$ bar);

- Filtration of iodine volatile species including organic iodides.

Several series of tests have been performed by VTT and the following points can be stated.

From tests at room conditions, using $\mathrm{TiO}_{2}$ aerosols, a strong decrease of the trapping efficiency for voltages below $15 \mathrm{kV}$ (negative) was evidenced. Using gaseous and particulate iodine, the optimum parameters related to the operation of the applied WESP have been determined (number of corona needles, effect of the gas flow residence time, etc...) leading to a very good efficiency for gaseous $\mathrm{I}_{2}$ filtration in dry conditions. A fitting of curves to experimental data has been done.

Other tests have been performed at higher temperature $\left(60^{\circ} \mathrm{C}\right)$ in presence of steam, confirming the utility of different process steps (oxidation of $\mathrm{I}_{2}$ or $\mathrm{CH}_{3} \mathrm{I}$ into iodine oxide (IOx) particles, $\mathrm{NaOH}$ droplets spraying, electrical filter wall flushing) (Gouëllo et al., 2017). The presence of steam in the atmosphere can have a significant impact on the filtration efficiency of the device. For the two tested concentrations of $\mathrm{I}_{2}$ (the theoretically estimated concentrations of 3200 and $7500 \mathrm{ppm}$ at the oxidation stage), increasing the amount of steam in the carrier gas increases the retention of iodine in the WESP. In the case of lower concentration of gaseous iodine, the increase in the filtration efficiency was from 99.7 to $99.9 \%$ for particle number (online measurement in the gas phase), when the steam fraction became threefold. The effect of steam was more prominent for the higher iodine concentration; the increase in the filtration efficiency was from 96.8 to $99.9 \%$. On the basis of ICP-MS analyses of the total mass of iodine in the filter and bubbling bottle samples, for both concentrations (Gouëllo et al., 2017), the filtration efficiency for molecular iodine remained in a range from 97.6 to $99.9 \%$ constantly. Fig. 14 provides an example of the lower iodine concentration case. The filtration efficiency results were varying slightly depending on the analysis technique, e.g. gas phase measurement of the number of aerosol particles vs. ICP-MS analysis of the collected aerosol particles on filter samples.

The filtration efficiency for $\mathrm{CH}_{3} \mathrm{I}$ (at the theoretically estimated concentration of $16,300 \mathrm{ppm}$ at the oxidation stage) was lower than for $\mathrm{I}_{2}$. The results from ICP-MS analyses showed very low filtration efficiency, being in a range from 41 to $84 \%$ for the total mass of iodine (gas and particles). However, the filtration efficiency for the particle fraction was on a high level ranging up to $97 \%$. At the inlet of the WESP, only $5 \%$ of iodine was in the form of particles and $95 \%$ was in the gaseous form. Whereas in the case of $I_{2}$ tests, more than $96 \%$ of iodine mass was in the form of particles and less than $4 \%$ was in the gaseous form at the WESP inlet. As the rapid oxidation of both $\mathrm{I}_{2}$ and $\mathrm{CH}_{3} \mathrm{I}$ into IOx particles has been observed in the previous tests of VTT (Kärkelä et al., 2009; Kärkelä et al., 2010), it seemed that the concentration of ozone was not high enough to convert all gaseous $\mathrm{CH}_{3} \mathrm{I}$ into iodine oxide particles in these new tests with WESP. That was due to unexpectedly too high concentration of $\mathrm{CH}_{3}$ I generated in the WESP tests. On the other hand, iodine oxide particles are also known to decompose to iodic acid and $\mathrm{I}_{2}$ in humid atmosphere at elevated temperature

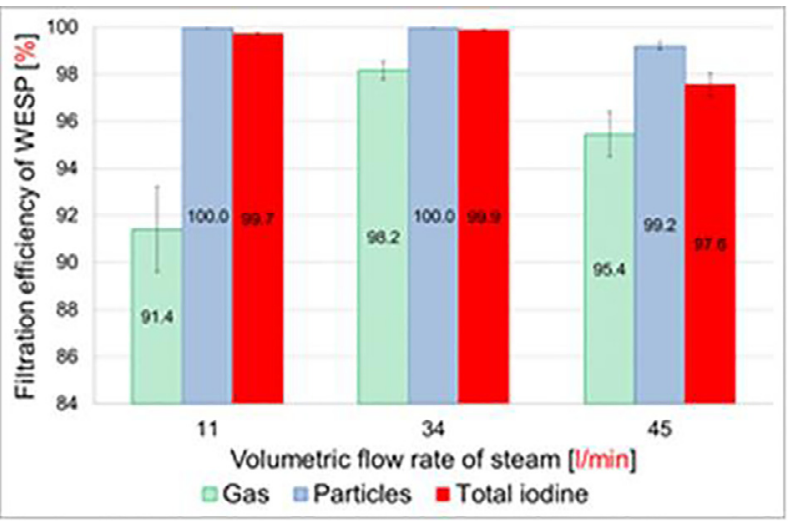

Fig. 14. Filtration efficiency for molecular iodine (gas, particles, sum) based on the ICP-MS analysis data of particle filter and bubbling bottle samples. The concentration of $\mathrm{I}_{2}$ gas in the oxidation stage was $3200 \mathrm{ppm}$. The figure was given in Gouëllo et al. (2017).

conditions (Kärkelä et al., 2015), which may have partly affected the obtained particle filtration efficiency results.

Despite this last result showing a non-satisfactory efficiency for total organic iodine due to experimental error, the work has shown that VTT's innovation to use "ozone feed and WESP" together enables the filtration of both gaseous iodine and iodine containing particles (e.g. $\mathrm{I}_{\mathrm{x}} \mathrm{O}_{\mathrm{y}}$ ). However, it has to be kept in mind that the filtration efficiency strongly depends on the WESP design/geometry optimization and the WESP should be fitted according to the specific application. The location of the oxidation step closer to the WESP inlet need to be further tested in order to avoid possible particle decomposition before the filtration step and therefore, to increase the filtration efficiency against organic iodine.

\subsection{Experimental studies of improved zeolites (Leader IRSN - Main contributor University of Lorraine)}

Zeolites are crystalline materials containing pores of molecular size (5-12 $\AA$ ). They are composed of $\left[\mathrm{SiO}_{4}\right]^{4-}$ and $\left[\mathrm{AlO}_{4}\right]^{5-}$ tetrahedra linked by oxygen atoms. The substitution of the $\mathrm{Si}^{4+}$ by $\mathrm{Al}^{3+}$ leads to a negative charge, which is compensated by the presence of a metallic (M) cation of $n$ valence $\left(\mathrm{M}_{\mathrm{x} / \mathrm{n}}\left[\mathrm{AlO}_{2}\right]_{\mathrm{x}}\left[\mathrm{SiO}_{2}\right]_{\mathrm{y}} \mathrm{zH}_{2} \mathrm{O}\right.$, where $\mathrm{y} / \mathrm{x}$ (the $\mathrm{Si} / \mathrm{Al}$ ratio) should be higher than 1 . Several zeolite families are presently being used as sorbents or catalysts in different industrial processes: Faujasite (FAU X and Y), Mordenite (MOR), ZSM-5 (MFI), Ferrierite (FER) and others. Since the 70's, a number of studies have been conducted to assess the zeolites capability for iodine retention (Pence et al., 1970; Choi et al., 2001, 2003) and among all the metallic cations tested $\left(\mathrm{Cd}^{2+}, \mathrm{Pb}^{2+}, \mathrm{Na}^{+}\right.$, $\left.\mathrm{Cu}^{2+} / \mathrm{Cu}^{+} \ldots\right)$ silver gives the best filtering efficiency for potential nuclear applications. Two types of silver-containing solids have been successfully tested for iodine trapping: silver mordenite (AgZ) and silver faujasite (AgX). The trapping mechanism seems to involve chemical redox reactions with some embedded Ag species, which results in the formation of a stable insoluble iodine AgI precipitate.

Literature studies have given only few insights on iodine capture by silver zeolites in the context of severe accidents. The Faujasite Ag-X adsorbents showed high retention efficiencies for both molecular iodine and organic iodides, but the efficiency is decreased in presence of steam and nitrogen oxides (NOx). In Mordenite, $\mathrm{I}_{2}$ chemisorption was reported to be enhanced if metallic silver is present but the effect of particle size is not clear (Chapman et al., 2010). High humidity affects negatively organic iodide trapping. However, silver zeolites are robust and are sup- 
posed to withstand harsh temperature, humidity and radiation conditions.

In spite of all the knowledge gathered concerning iodine trapping in zeolites, little information is available concerning impacts of zeolite structure, chemical properties (Si/Al ratio...) and silver content. The persistence of high iodine retention efficiency under boundary conditions relevant to FCVS (oxidizing conditions resulting from radiation, presence of inhibitors such as humidity, COx, NOx, $\mathrm{H}_{2}$, chlorine. ..) is also questionable.

More precisely, the experiments in the frame of the PASSAM project focused on:

- the optimization of the nature of the zeolite (structure, chemical properties) in order to avoid poisoning effects and to obtain high iodine retention efficiencies;

- the definition of optimal active sites for the trapping of iodine and organic iodides (deeper understanding of the trapping mechanisms);

- providing extensive and sound data on the effect of expected severe accident working conditions including the influence of chemicals (steam and gas contaminants which could lead to sorbent poisoning) and irradiation effects on iodine trapping capacity.

Among the extensive quantity of results acquired by the French University of Lorraine ( $\mathrm{LCP}-\mathrm{A}_{2} \mathrm{MC}$ laboratory), the following ones can be highlighted.

- About 15 different silver zeolites differing by their structure (FAU $\mathrm{X}$ and $\mathrm{Y}, \mathrm{FER}, \mathrm{MOR}, * \mathrm{BEA}, \mathrm{MFI}$ ) and chemical properties ( $\mathrm{Si} / \mathrm{Al}$ in the range $1.2-40, \mathrm{Ag}$ content in the range $0-35 \mathrm{wt} \%$ were investigated for iodine capture. Their useful working capacities are plotted on Fig. 15(A) for $\mathrm{CH}_{3} \mathrm{I}$. Superior filtering properties were obtained for the faujasite $\mathrm{Ag} / \mathrm{Y}$ zeolites and to a lesser extent for $\mathrm{Ag} / \mathrm{MOR}$ and $\mathrm{Ag} / \mathrm{ZSM}-5$. Although the presence of defects in zeolite crystallites could also negatively impact iodine diffusion and trapping, one of the most important parameters towards $\mathrm{CH}_{3} \mathrm{I}$ retention (and also $\mathrm{I}_{2}$ retention to a lesser extent) is the amount of silver that could be deposited in dispersed form (as $\mathrm{Ag}^{+}$cations or small embedded clusters of a few atoms, as indicated by physico-chemical characterization data, not shown here). In that respect, the Si/Al ratio, the zeolite type and the preparation method (ion-exchange or impregnation) impact the silver dispersion and oxidation state. Practically, a high silver content in dispersed form could be achieved through repeated ionic exchanges with some zeolitic structures, such as large-pore faujasite (>20 wt\%), which have high cationic exchange capacities according to their formula ( $\mathrm{Si} / \mathrm{Al}<5)$. By contrast, silver impregnated zeolites, which do not have an appreciable exchange capacity (high Si/Al ratio, almost full-silica hydrophobic zeolites), were characterized by poorer iodine retention properties due to the presence of aggregated silver. In $\mathrm{Ag}^{0}$ nanoparticles, the surface-to-bulk diffusion of iodine seems to be kinetically and thermodynamically restricted and this also limits the amount of silver atoms that could react to form stable AgI precipitates (unlike the case of exchanged zeolites).

- Faujasite $\mathrm{Ag} / \mathrm{Y}$ and $\mathrm{Ag} / \mathrm{X}$ sorbents with more than $15 \mathrm{wt} \%$ silver (and to a lesser extent $\mathrm{Ag} / \mathrm{MOR}$ and $\mathrm{Ag} / \mathrm{ZSM}-5$ ) displayed the highest ability for irreversible iodine trapping (AgI and to a lesser extent other chemisorbed fractions $>85-90 \%$, Fig. 15(B)). Overall, all silver-exchanged zeolites behave rather well for $\mathrm{CH}_{3} \mathrm{I}$ and $\mathrm{I}_{2}$ retention except the silver ferrierite, which showed about $60 \%$ of reversible adsorption due to its small-pore size. It can be concluded that the trapping stability depends on the availability of silver sites to promote silver iodide formation.
Among all investigated silver zeolites, a large-pore faujasite zeolite of $\mathrm{Y}$ type with $\mathrm{Si} / \mathrm{Al}$ ratio $=2.5$ and $23 \mathrm{wt} \%$ of silver, displayed the best retention performances towards volatile iodine species (adsorption capacities for $\mathrm{CH}_{3} \mathrm{I}$ and $\mathrm{I}_{2}$, respectively, at $100{ }^{\circ} \mathrm{C}$ - at saturation 209 and $380 \mathrm{mg} / \mathrm{g}$ - at breakthrough 90 and $330 \mathrm{mg} / \mathrm{g}$, Retention efficiency $=99.999 \%$ (during 9 days with $\left[\mathrm{CH}_{3} \mathrm{I}\right]=1 \mathrm{ppm}$, Fig. $15(\mathrm{C})$ ), up to $80 \%$ of storage as $\mathrm{AgI}$ precipitates).

- The adsorption temperature has only little influence on the $\mathrm{CH}_{3} \mathrm{I}$ sorption properties of $\mathrm{Ag} / \mathrm{Y}$ sorbent in the range of $35-250{ }^{\circ} \mathrm{C}$, the production of catalytic by-products (oxygenates, higher hydrocarbons) being promoted at the expense of physisorption at higher temperatures.

- The impact of irradiation was studied at IRSN. An irradiation (total dose of $1.14 \mathrm{MGy} ;{ }^{60} \mathrm{Co}$ source, IRMA facility) of $\mathrm{Ag} / \mathrm{Y}$ sorbent before test did change neither its physico-chemical characteristics nor its retention performances towards $\mathrm{I}_{2}$ and $\mathrm{CH}_{3} \mathrm{I}$. Moreover, the trapping stability of $\mathrm{I}_{2}$ under irradiation and in very humid conditions $\left(\mathrm{T}=120^{\circ} \mathrm{C}\right.$, dose rate of $2.9 \mathrm{kGy} / \mathrm{h}, \mathrm{R} . \mathrm{H}$ $=60 \%, 29 \mathrm{~h}$ ) has been also checked (EPICUR facility at IRSNCadarache) using a commercial silver faujasite (X type) with $35 \%$ wt of silver. No measurable release of iodine species was observed confirming therefore the high stability of trapping thanks to the formation of stable and insoluble AgI precipitates. This good behaviour was confirmed for $\mathrm{CH}_{3}{ }^{131}$ I retention in a representative test carried out in PERSEE loop at IRSN-Saclay $\left(24{ }^{\circ} \mathrm{C}, 8 \mathrm{~L} / \mathrm{min}\right.$ wet air flow with $\left.\mathrm{R} . \mathrm{H}=71 \%\right)$. A retention efficiency of $99.5 \%$ was obtained.

- Under tested conditions $\left(\mathrm{T}=100^{\circ} \mathrm{C}, \mathrm{CH}_{3} \mathrm{I}: \mathrm{CO}=5: 1, \mathrm{CH}_{3} \mathrm{I}: \mathrm{H}_{2} \mathrm{O}=\right.$ $\left.1: 8, \mathrm{CH}_{3} \mathrm{I}: \mathrm{H}_{2}=1: 12.5\right)$, the presence of $\mathrm{CO}, \mathrm{H}_{2} \mathrm{O}$ or $\mathrm{H}_{2}$ in the feed gas had only little or no impact on $\mathrm{CH}_{3} \mathrm{I}$ retention by $\mathrm{Ag} / \mathrm{Y}$ faujasite zeolite. However, the presence of significant amounts of $\mathrm{NO}_{2}\left(\mathrm{CH}_{3} \mathrm{I}: \mathrm{NO}_{2}=2: 1\right)$ induced a partial oxidation of $\mathrm{CH}_{3} \mathrm{I}$ to $\mathrm{I}_{2}$, the latter being released from the sorbent bed. A preliminary exposure to chlorinated species also promotes some poisoning of active silver sites (by formation of $\mathrm{AgCl}$ ), making them less efficient for iodine trapping. Nevertheless, it should be acknowledged that additional tests should be performed in more representative conditions (mixture of inhibitors, more representative concentrations, irradiation...) to be more conclusive.

- For the first time, a combination of several spectroscopic techniques under in situ conditions (gas-phase FTIR, DRIFTS and DRS-UV-Vis) was used to unravel the $\mathrm{CH}_{3}$ I trapping mechanism. Detailed mechanistic schemes relevant to the nucleation and growth of AgI precipitates in the sorbent pores and to the catalytic decomposition of $\mathrm{CH}_{3} \mathrm{I}$ to different organic species, were obtained.

\subsection{Experimental studies of "combined" filtration systems (leader AREVA)}

The AREVA FCVS is based on an extensive series of laboratory tests and further large-scale investigations. As a result, a combined retention process was selected, consisting of complementary wet scrubbing and particulate filtering. The AREVA FCVS standard comprises a venturi scrubber unit consisting of a venturi section (wet section), a combined droplet separator and metal fibre filter section (dry section) combined with a throttling orifice for a sliding pressure process (Fig. 16, left). Sliding pressure operation means that the pressure is close to the containment pressure and reduced only downstream of the venturi scrubber and metal fibre filter section. By the entrainment and dispersion of the scrubbing liquid, large reaction surfaces are created in the venturi nozzles which result in an additional effective sorption of gaseous iodine. For optimum iodine retention, the scrubbing liquid is conditioned with caustic soda and other additives. 
(A) useful working capacities $\left(\mathrm{CH}_{3} \mathrm{I}\right)$

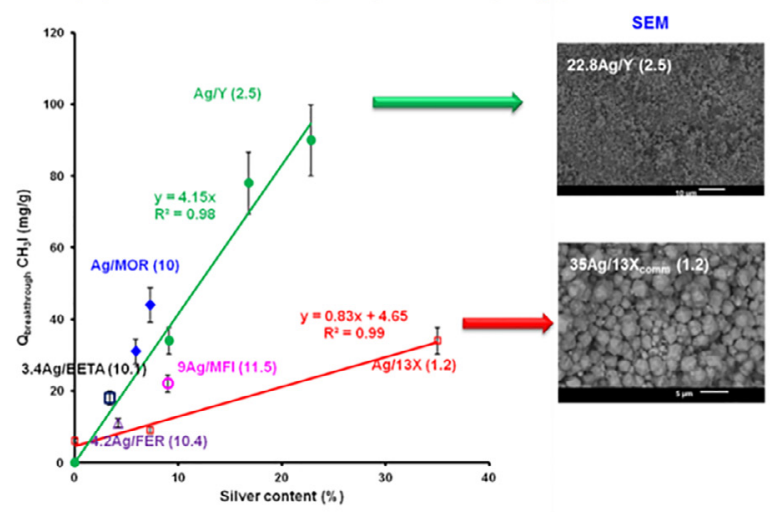

(B) Trapping stability $\left(\mathrm{CH}_{3} \mathrm{I}\right)$

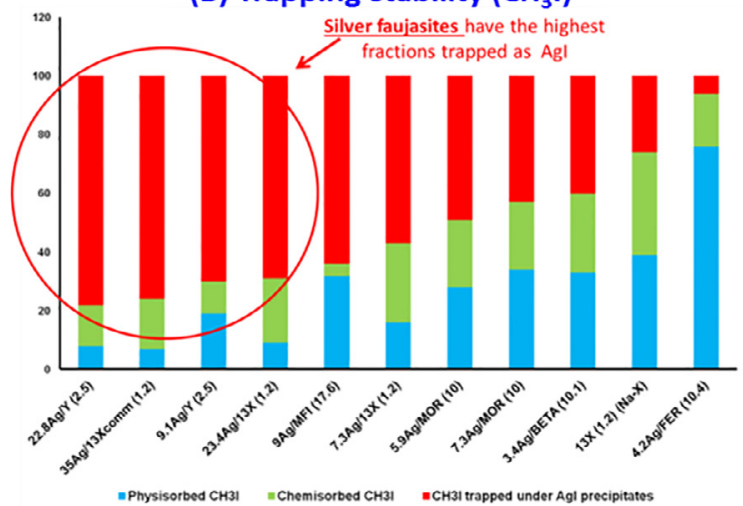

(C) $\mathrm{CH}_{3}$ I decontamination factors (faujasite zeolites)

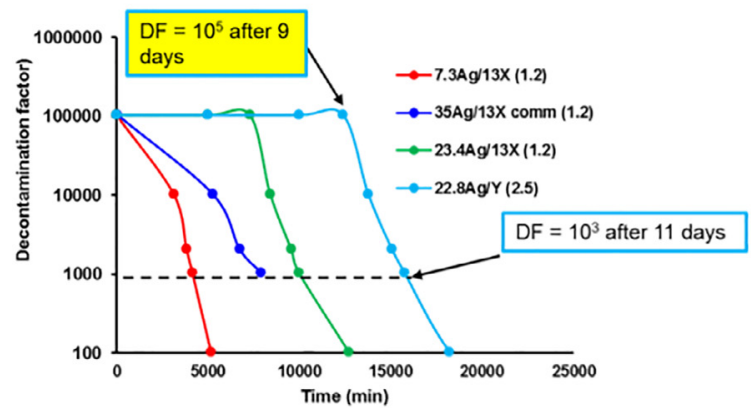

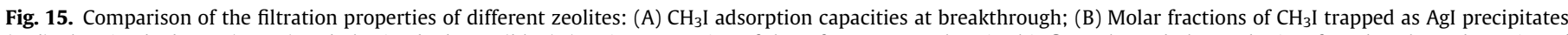

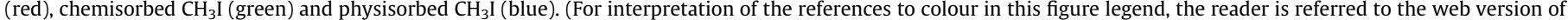
this article.)
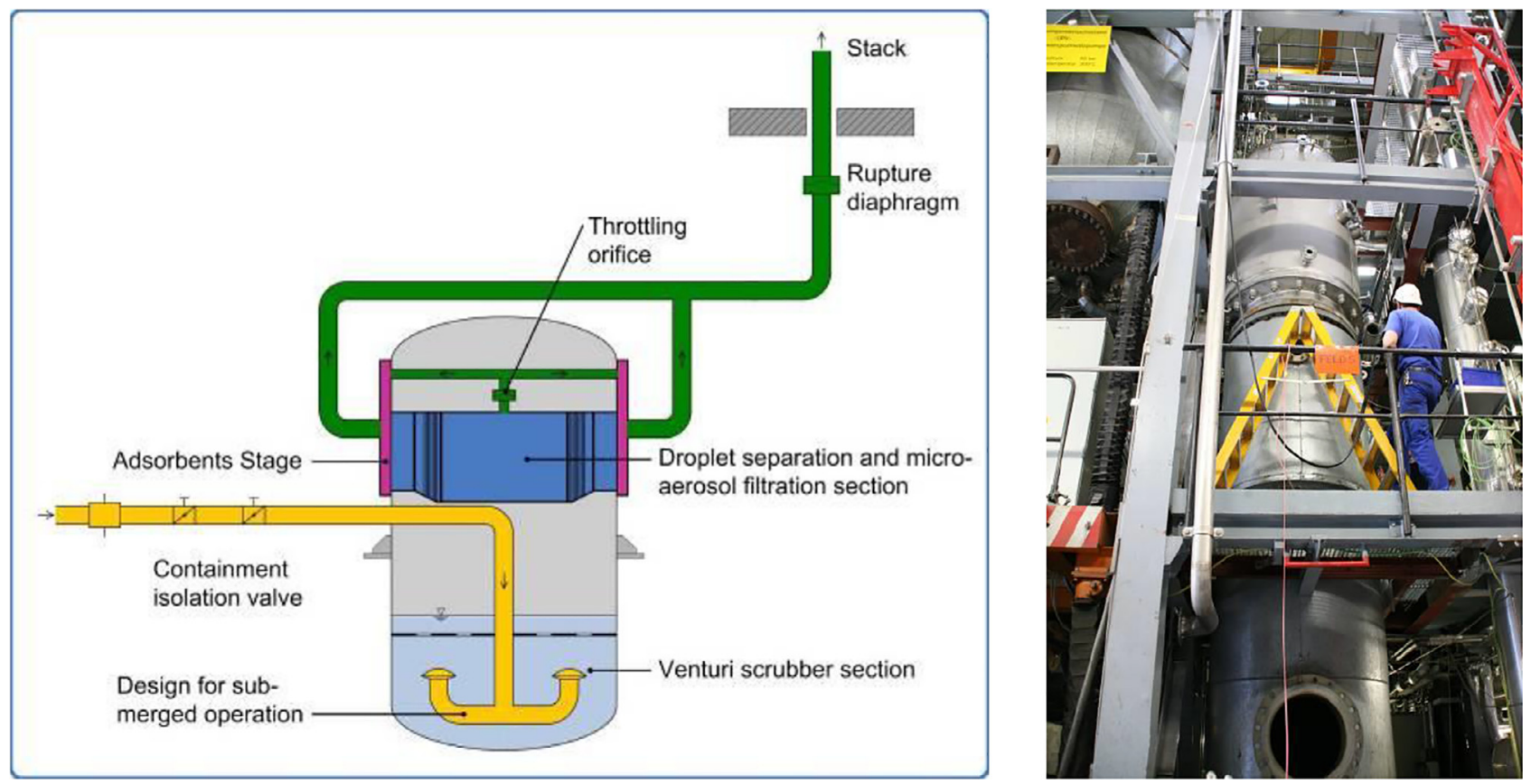

Fig. 16. AREVA FCVS scheme (left) and JAVA PLUS facility (right).

The AREVA FCVS provides already retention efficiencies higher than $99.99 \%$ for aerosols (even those smaller than $0.5 \mu \mathrm{m}$ ) and higher than $99.5 \%$ for $I_{2}$. Despite this performance, as it is reminded in Part 3.1.5 of this paper, several studies (Clément et al., 2007) indicate that a significant generation of organic iodine in the con- tainment atmosphere might occur during a severe accident. Consequently the AREVA FCVS Plus was developed by supplementing the existing AREVA FCVS Standard with a sorbent (zeolite) section as a third retention stage with combined passive superheating downstream of the throttling orifice. 
In link with the PASSAM project, the AREVA experimental programme on this "FCVS PLUS" combined system was completed in 2013. The main results on organic iodine retention as stated by AREVA are:

- Retention efficiency of zeolite depends upon many parameters: sorbent material, geometry/flow dynamics, superheating/relative humidity, heat repartition, residence time, gas composition, flow velocities, etc.

- Extensive large scale test campaigns were conducted at the JAVA PLUS test facility (Fig. 16, right). The performed JAVA PLUS tests verified that this combined filter is able to retain more than $98 \%$ of organic iodine.

- The studied parameters allowed developing a model in order to customize the retention efficiency for organic iodine by appropriate design of the sorbent stage for the requested operating range.

The performed test campaign resulted in a fully qualified combined filter design of this "FCVS PLUS".

\section{Conclusions}

Thanks to the four year (2013-2016) European PASSAM project, databases on existing or innovative mitigation systems have been extended.

Concerning existing systems, extensive studies on pool scrubbing led to a better understanding of hydrodynamics in the jet injection regime (although complementary experiments should be done) and in SGTR situation with the secondary side still flooded. The effect of sea water and water with surfactant was also studied and the effect on the decontamination factor for aerosol was evidenced. In addition, potential delayed release of iodine trapped in a scrubber solution was observed and analyzed. Finally a study on trapping of organic iodine by scrubbing concluded to a non-sufficient retention, in spite of many different solutions studied. Sand filters and metallic pre-filters (French system) were also studied as solid filtration systems. It was confirmed that organic iodides are not trapped by these systems while molecular gaseous iodine may be trapped on the metallic prefilter. It was also evidenced that CsI aerosols trapped on the sand filter may lead to a delayed release due to the non-stability of CsI under temperature and irradiation.

Concerning innovative systems, acoustic agglomerators, high pressure sprays and wet electrostatic precipitators (coupled to an ozoner in order to transform gaseous iodine into particles of iodine oxides) showed potential interesting performances. Nevertheless, their applicability as FCVS or as pre-conditioners upstream of a FCVS is not straightforward. A large experimental data set was obtained on zeolites, in particular on their high capacity for trapping gaseous iodine, including organic iodides. The stability of iodine trapped by zeolites was confirmed under temperature and irradiation. Finally, a combined wet (pool scrubber operated at the pressure of the containment) and dry (zeolite operated at atmospheric pressure) was developed and studied in "representative" conditions. It showed a retention efficiency for organic iodine above $98 \%$.

Globally, in-depth analysis of the experimental results allowed a deeper understanding of the phenomena involved in the performance of the mitigation systems studied, and simple models or correlations which should be easy to implement in accident analysis codes, like ASTEC (Chatelard et al., 2015) could be proposed for several PASSAM experimental studies.

The main technical outcomes of the project were presented in a final workshop held on February 28th and March 1st, 2017 in Paris
(France) and documented with more details in the final synthesis report of the project. Note that all the public documents of the project are available on a dedicated PASSAM web site at https://gforge. irsn.fr/gf/project/passam/.

\section{Acknowledgments}

The authors thank the European Atomic Energy Community (Euratom) for showing a strong interest in the PASSAM Project, and for funding it in the frame of the 7th framework programme FP7/2007-2013 under grant agreement $n^{\circ} 323217$.

The authors also thank the many contributors who performed the work in each PASSAM partner organization.

\section{References}

Allelein, H.J., Auvinen, A., Ball, J., Guentay, S., Herranz, L.E., Hidaka, A., Jones, A., Kissane, M., Powers, D., Weber, G., 2009. State-of-the-art on nuclear aerosols, OECD/NEA/CSNI/R(2009) 5, pp. 248-255.

Betschart, T., Lind, T., Suckow, D., Brankov, V., Prasser, H.-M., 2015. Two-phase flow hydrodynamics characterization for understanding the aerosol retention in liquid pools. In: 7th European Review Meeting on Severe Accident Research (ERMSAR 2015), Marseille (France), March 24-26, 2015.

Chang, J., Dong, Y., Wang, Z., Wang, P., Chen, P., Man, C., 2011. Removal of sulphuric acid aerosol in a wet electrostatic precipitator with single terylene or polypropylene collection electrodes. J. Aerosol. Sci. 42, 544-554.

Chapman, K.W., Chupas, P.J., Nenoff, T.M., 2010. Radioactive iodine capture in silvercontaining mordernites through nanoscale silver iodide formation. J. Am. Chem. Soc. $132,8897-8899$.

Chatelard, P., Belon, S., Bosland, L., Coindreau, O., Cousin, F., Marchetto, C., Nowack, H., Piar, L., 2015. Focus on the main modelling features of ASTEC V2.1 major version. In: 7th European Review Meeting on Severe Accident Research (ERMSAR 2015), Marseille (France), March 24-26, 2015.

Choi, B.S., Park, G.I., Kim, J.H., Lee, J.W., Ryu, S.K., 2001. Adsorption equilibrium and dynamics of methyl iodide in a silver ion-exchanged zeolite column at high temperatures. Adsorption 7, 91-103.

Choi, B.S., Park, G.I., Lee, J.W., Yang, H.Y., Ryu, S.K., 2003. Performance test of silver ion-exchanged zeolite for the removal of gaseous radioactive methyl iodide at high temperature condition. J. Radioanal. Nucl. Chem. 256, 19-26.

Chuen-Jinn, T., Chia-Hung, L., Yu-Min, W., Cheng-Hsiung, H., Shou-Nan, L., ZongXue, W., Feng-Cai, W., 2005. An efficient venturi scrubber system to remove submicron particles in exhaust gas. J. Air Waste Manage. Assoc. 55, 319-325.

Clément, B., Cantrel, L., Ducros, G., Funke, F., Herranz, L. E.A., Rydl, G., 2007. Weber and C. Wren, "State of the art report on iodine chemistry", OECD/NEA/CSNI/R (2007) 1.

Gouëllo, M., Hokkinen, J., Kärkelä, T., Auvinen, A., 2017. Combination of Ozone Feed and Wet Electrostatic Precipitator: Experimental Study of An Innovative System to Filter Gaseous Iodine and Iodine Containing Particles. In: Proceedings of the ICAPP2017 International Congress on Advances in Nuclear Power Plant, Fukui and Kyoto (Japan), April 24-28, 2017.

Guieu, S., 2001. Prevention of Delayed Containment Failure: the Sand-Bed Filter. Characteristics and Role in Severe Accident Management. In: Proceedings of the OECD/SAMI Workshop on the implementation of severe accident management measures, OECD/NEA/CSNI/R(2001) 20, PSI Report Nr. 01-15 (2001).

Guieu, S., 2014. French NPPs Filtered Containment Venting design. In: 33rd Nuclear Air Cleaning Conference, Saint Louis (MO, USA), June 22-24, 2014.

Herranz, L.E., Lind, T., Dieschbourg, K., Riera, E., Morandi, S., Rantanen, P., Chebbi, M., Losch, N., 2013. PASSAM "State-of-the-art report" - Technical Bases for Experimentation on Source Term Mitigation Systems, PASSAM-THEOR-T04 [D2.1], (2013). https://gforge.irsn.fr/gf/project/passam/docman/PUBLIC\% 20FILES/.

Herranz, L.E., Lind, T., Mun, C., Riera, E., Morandi, S., Rantanen, P., Azambre, B., Losch, N., 2014a. "PASSAM Experimental Tests Matrixes", PASSAM-THEOR-T06 [D2.2], (2014), https://gforge.irsn.fr/gf/project/passam/docman/PUBLIC\%20FILES/.

Herranz, L.E., Delgado, R., Berschart, T., Lind, T., Morandi, S., 2014b. Remaining issues on pool scrubbing: Major drivers for experimentation within the EU-PASSAM project. In: Proceedings of ICAPP '14, Charlotte (NC, USA), April 6-9, 2014.

Jacquemain, D., Guentay, S., Basu, S., Sonnenkalb, M., Lebel, L., Allelein, H.J., Liebana Martinez, B., Eckardt B., Ammirabile, L., 2014. Status Report on Filtered Containment Venting, OECD/NEA/CSNI/R(2014) 7.

Kärkelä, T., Holm, J., Auvinen, A., Zilliacus, R., Tapper, U., 2009. Experimental study on iodine chemistry (EXSI) - Containment experiments with elemental iodine, VTT Research report VTT-R-00717-09 (2009).

Kärkelä, T., Holm, J., Auvinen, A., Zilliacus, R., Kajolinna, T., Tapper, U., Glänneskog, H., Ekberg, C., 2010. Gas phase reactions of organic iodine in containment conditions, In: Proceedings of ICAPP 2010, San Diego, CA, USA, June 13-17, 2010.

Kärkelä, T., Auvinen, A., Kekki, T., Kotiluoto, P., Lyyränen, J., Jokiniemi, J., 2015. Radiolytical oxidation of gaseous iodine by beta radiation. Radiochim. Acta 103 (10), 719-728. 
Lind, T., Dehbi, A., Guentay, S., 2011. Aerosol retention in the flooded steam generator bundle during SGTR. Nucl. Eng. Des. 241, 357-365.

Lind, T., Losch, N., Herranz, L., Mun, C., Morandi, S., 2015. Advances on understanding of pool scrubbing for FCVS based on the PASSAM project. In: IAEA: I3-TM-50122 Technical Meeting on Severe Accident Mitigation, Vienna, 31 August to 3 September 2015.

Magill, J., Pickering, S., Fourcaudot, S., Gallego-Juárez, J.A., Riera, E., Rodriguez, G. 1989. Acoustic aerosol scavenging. J. Nucl. Mater. 166, 208-213.

PASSAM 1st Workshop on source term mitigation of severe accidents, Madrid(Spain), February 26th, 2014, https://gforge.irsn.fr/gf/project/passam/docman/PUBLIC\% 20FILES/PASSAM\%201st\%20Workshop\%20Madrid\%20Feb\%2026,\%202014/.
Pence, D.T., Duce, F.A., Maeck, W.J., 1970. A Study of the Adsorption properties of metal zeolites for airborne iodine species. In: Proceedings of the 11th AEC Air Cleaning Conference, Richland (WA, USA), August 31 - September 3, 1970.

Powers, D. Burson, S.B., 1993. A Simplified Model of Aerosol Removal by Containment Sprays, NUREG/CR-5966, SAND92-268 (1993).

Riera, E., Elvira, L., González, I., Rodríguez, J.J., Muñoz, R., Dorronsoro, J.L., 2003. Investigation of the influence of humidity on the ultrasonic agglomeration of submicron particles in diesel exhausts. Ultrasonics 41, 277-281.

Riera, E., Gallego-Juárez, J.A., Mason, T.J., 2006. Airborne ultrasound for the precipitation of smokes and powders and the destruction of foams. Ultrason. Sonochem. 13, 107-116. 